\title{
Preparation and Photocatalytic Performance of Nano-TiO Codoped with Iron III and Lanthanum III
}

\author{
Wei Guan, Fangying Ji, Zhigang Xie, Rongan Li, and Nan Mei \\ Chongqing Key Laboratory of Environmental Materials \& Remediation Technologies, \\ Chongqing University of Arts and Sciences, Chongqing 402160, China
}

Correspondence should be addressed to Fangying Ji; jfy@cqu.edu.cn

Received 23 October 2014; Revised 20 January 2015; Accepted 27 January 2015

Academic Editor: Donglu Shi

Copyright (c) 2015 Wei Guan et al. This is an open access article distributed under the Creative Commons Attribution License, which permits unrestricted use, distribution, and reproduction in any medium, provided the original work is properly cited.

Nanoscale titanium dioxide (nano- $\mathrm{TiO}_{2}$ ) was modified via metal doping to improve its photocatalytic activity and utilization of visible light. Nano-TiO 2 doped with iron III $\left(\mathrm{Fe}^{3+}\right)$ only, lanthanum III $\left(\mathrm{La}^{3+}\right)$ only, and both $\mathrm{Fe}^{3+} / \mathrm{La}^{3+}$ was prepared using the sol-gel method. The photocatalytic activities of the three forms of doped nano- $\mathrm{TiO}_{2}$ were evaluated. Metal codoping limited crystal growth of crystal, and the sol-gel method was shown to be an effective technique for doping the lattice of $\mathrm{TiO}_{2}$ with $\mathrm{Fe}^{3+}$ and $\mathrm{La}^{3+}$. Codoping of nano- $\mathrm{TiO}_{2}$ with the tombarthite metal mixture had a synergistic effect of the photocatalytic performance, with the codoped nano- $\mathrm{TiO}_{2}$ exhibiting a performance greater than the sum of those of the single-doped nano-TiO ${ }_{2}$ samples. Kinetic studies showed that the photodegradation reaction of methyl orange by nano- $\mathrm{TiO}_{2}$ follows the Langmuir-Hinshelwood first order mechanism.

\section{Introduction}

Global environmental pollution and energy shortages are becoming increasingly serious problems $[1,2]$. The control of environmental pollution has become a major and urgent topic of concern. In 1972, Fujishima and Honda published the first article in Nature declaring that the semiconductor titanium dioxide crystal electrode has the ability to photocatalytically split water to produce hydrogen $[3,4]$. This discovery signaled the beginning of heterogeneous photocatalysis research in the area of semiconductors. Photocatalysis technology, as a representative of green chemistry, is widely applied in many areas, such as wastewater treatment, air purification, and solar energy transfer and storage [5-7].

Nanoscale titanium dioxide $\left(\right.$ nano- $\mathrm{TiO}_{2}$ ) has become a preferred material for these applications due to its high catalytic activity and stable chemical properties and because it is cheap and nontoxic [8-10]. However, there are some disadvantages of using nano- $\mathrm{TiO}_{2}$, such as the high recombination rate of photoproduced electron-hole pairs, low quantum efficiency, and poor photocatalytic performance [912]. Nano- $\mathrm{TiO}_{2}$ can only use the ultraviolet portion of the solar spectrum range (only $3-5 \%$ of the total range) due to a wide band gap $(3.2 \mathrm{eV})$, which leads to low effective utilization of sunlight [13-15]. Researchers have used a variety of methods to modify nano- $\mathrm{TiO}_{2}$, including noble metal modification, compound semiconductor, dye sensitization, metal ion doping, and others [16-19]. With these modification methods, the recombination rate of photogenerated electron-hole pairs of nano- $\mathrm{TiO}_{2}$ photocatalyst is decreased, and the photocatalysis efficiency and range of visible light that generates a response are increased [20-23]. Our research group found that modification by codoping with two elements can increase the visible light photocatalytic activity of nano- $\mathrm{TiO}_{2}$.

The main aim of the present study was to increase the visible light photocatalytic activity of nano- $\mathrm{TiO}_{2}$. The originality and significance of this study are described as follows.

(1) We prepared nano- $\mathrm{TiO}_{2}$ photocatalysts by doping of nano- $\mathrm{TiO}_{2}$ powder with iron III ions $\left(\mathrm{Fe}^{3+}\right)$, lanthanum III ions $\left(\mathrm{La}^{3+}\right)$, or both via the sol-gel method.

(2) The microstructure and chemical composition of the prepared nano- $\mathrm{TiO}_{2}$ photocatalysts were analyzed by X-ray diffraction (XRD), X-ray photoelectron 
spectroscopy (XPS), fluorescence spectroscopy (FS), and UV-Visible absorption spectroscopy (UV-Vis). Furthermore, the catalytic mechanism was revealed in the present study.

(3) The effects of various parameters, such as the roasting temperature, roasting time, catalyst dosage, initial $\mathrm{pH}$ value, doping amount, and doping type on the photocatalytic activity were investigated. In conclusion, a new mechanism for metal doping of nano- $\mathrm{TiO}_{2}$ was proposed.

\section{Experimental Section}

2.1. Preparation of Nano-TiO 2 Photocatalysts. The preparation process for nano- $\mathrm{TiO}_{2}$ photocatalysts is shown in Figure 1. First, $100 \mathrm{~mL}$ absolute ethanol and $5 \mathrm{~mL}$ glacial acetic acid were added to a $250 \mathrm{~mL}$ beaker. After magnetic stirring for $30 \mathrm{~min}$, the $\mathrm{pH}$ value of the solution was adjusted to 2 using nitric acid. The obtained mixture was designated solution A. Then, $15 \mathrm{~mL}$ ethanol and different doses (doping percentage is described as mole ratio) of modifier $\left(\mathrm{Fe}^{3+}\right.$ and/or $\mathrm{La}^{3+}$ ) were added to a separate beaker to obtain solution B. Solution B was then added to solution A to obtain solution $\mathrm{C}$. Then, $20 \mathrm{~mL}$ tetrabutyl titanate was added to the mixed solution $\mathrm{C}$, followed by the addition of $5 \mathrm{~mL}$ distilled water. This solution was then stirred for $4 \mathrm{~h}$. Sol $\mathrm{TiO}_{2}$ was obtained after sealing the container for 2 days. The sol $\mathrm{TiO}_{2}$ gradually formed nano- $\mathrm{TiO}_{2}$ upon drying, grinding, and heat treatment.

2.2. Characterization of Photocatalysts. The phase of the asprepared samples was analyzed using a Shimazu XRD-6000 $\mathrm{X}$-ray diffractometer with a copper target $(\mathrm{Cu} \mathrm{K} \alpha, \lambda=$ $0.15406 \mathrm{~nm}$ ), a voltage of $40.0 \mathrm{KV}$, and a current of $30.0 \mathrm{~mA}$.

Surface charge analysis was conducted using a British Kratos XPSAM800 multifunctional surface analysis electron spectrometer, with an Al target (1486.6 ev) X-ray gun operating under $12 \mathrm{kv} \times 15 \mathrm{ma}$ power. The analysis chamber background vacuum was $2 \times 10^{-7} \mathrm{~Pa}$, adopting FAT working style. The spectrometer was operated with $\mathrm{Cu} 2 \mathrm{P} 3 / 2(932.67 \mathrm{ev})$, Ag3d5 (368.30 ev), and Au4f7/2 (84.00 ev) prototype correction, and data were corrected using carbon pollution $\mathrm{Cls}$ (284.8 ev).

The compounds produced in photocatalyzed reactions were identified using UV-Vis absorption spectroscopic analysis. This study used a Shimadzu UV-Vis 2550 spectrophotometer (integrating sphere method) for fixed UV-Vis spectroscopy. A fixed amount of photocatalyst powder was placed in a quartz ware, using standard $\mathrm{BaSO}_{4}$ powder as a reference. Spectra were collected with a sweep rate of $1800 \mathrm{~nm} / \mathrm{min}$ and a scanning range of 300-650 $\mathrm{nm}$.

The molecular structures of reaction produces were analyzed by fluorescence spectroscopy (FS). This study used solid form testing with a fixed fluorescence intensity at a certain incident light wavelength $(275 \mathrm{~nm})$, and the results were combined with the experimentally determined photocatalytic activity to analyze the fluorescent light characteristics of the photocatalysts.

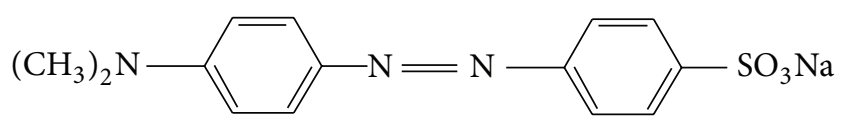

SCHEMe 1

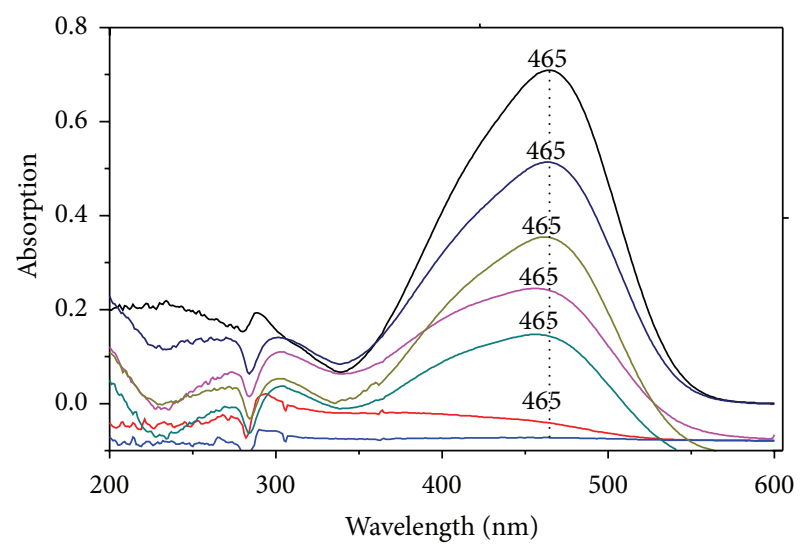

FIGURE 1: UV-Vis absorption spectra of methyl orange degradation catalyzed by $\mathrm{TiO}_{2}$.

\subsection{Evaluation of Photocatalyst Activity}

2.3.1. Target Compounds. This study used methyl orange (chemical name, dimethylamino azo benzene sulfonic acid sodium), which is produced by nitriding aminobenzene sulfonic acid via N, N-dimethylaniline coupling, as the target compound for assessing photocatalyst activity. The molecular formula of methyl orange is $\mathrm{C}_{14} \mathrm{H}_{14} \mathrm{O}_{3} \mathrm{~N}_{3} \mathrm{SNa}$. Its molecular weight is $327.34 \mathrm{Da}$, and its molecular structural contains a benzene group and $\mathrm{N}$ and $\mathrm{S}$ heteroatoms as shown in Scheme 1 [24].

Its molecular structure has certain representativeness. Remediation of methyl orange is a widespread problem, because this material is widely used as an industrial dye and is harmful to the aquatic environment. Methyl orange shows obvious absorption of visible light, as its absorbance and concentration have a linear relationship within a certain range, according to the Lambert-Beer law. In the continual degradation process of methyl orange, the maximum absorption wavelength has been at near $465 \mathrm{~nm}$, almost without deviation. The UV-Vis absorption spectra of methyl orange solution undergoing degradation with $\mathrm{TiO}_{2}$ photocatalyst is shown in Figure 1.

2.3.2. Photocatalytic Reaction Experiment. In a typical photocatalytic experiment, with a $30-\mathrm{W}$ UV lamp and $35-\mathrm{W}$ xenon lamp as light sources, $100 \mathrm{~mL}$ methyl orange solution $(10 \mathrm{mg} / \mathrm{L})$ and photocatalyst were added to five 300 $\mathrm{mL}$ beakers to form separate mixed suspensions. Prior to illumination, these mixed suspensions were stirred using a magnetic stirrer for $30 \mathrm{~min}$. Then, the mixed suspensions were illuminated (the distance from the liquid level to the UV lamp was $10 \mathrm{~cm}$ ) for $180 \mathrm{~min}$. The mixtures obtained after illumination were separated by centrifugation for $20 \mathrm{~min}$. 
2.3.3. Photocatalytic Activity Experiment. The photocatalytic activity of the as-prepared $\mathrm{TiO}_{2}$ samples was evaluated according to the decolorization rate of methyl orange solution. First, $100 \mathrm{~mL}$ methyl orange solution and a specified amount of $\mathrm{TiO}_{2}$ photocatalyst were placed in a homemade photocatalytic reaction container. After 30 min of magnetic stirring, the reaction mixture was illuminated using the UV lamp and xenon lamp. By measuring the absorbance of the solution at the maximum absorption wavelength of methyl orange $\left(\lambda_{\max }=465 \mathrm{~nm}\right)$, the decoloring rate can be calculated as follows:

$$
\eta=\frac{A_{0}-A_{t}}{A_{0}} \times 100 \%
$$

where $\eta$ is the decoloring rate, $A_{0}$ is the initial absorbance before illumination, and $A_{t}$ is the absorbance after illumination time, $t$.

\section{Results and Discussion}

3.1. Phase Distribution, Particle Size, and Lattice Distortion of the Prepared Nano-TiO $\mathrm{O}_{2}$ Photocatalysts. Figure 2 shows the $\mathrm{XRD}$ spectra for the different types of nano- $\mathrm{TiO}_{2}$ photocatalyst treated at $500^{\circ} \mathrm{C}$ for $2 \mathrm{~h}$. Compared to the standard X-ray spectrum of $\mathrm{TiO}_{2}$, it can be seen that the nano- $-\mathrm{TiO}_{2}$ powders and $\mathrm{Fe}^{3+} / \mathrm{La}^{3+}$ co-doped nano-TiO ${ }_{2}$ powders were anatase phase. As shown in Figure 2, the peak shapes of (101), (004), and (200) crystal plane diffraction was sharp, indicating that anatase phase had completely developed. Due to the small amounts of iron and lanthanide used for doping, no metal oxide diffraction peaks were observed corresponding to $\mathrm{Fe}^{3+}$ or $\mathrm{La}^{3+}$. According to previous reports, in the $\mathrm{La}^{3+}-$ doped nano- $-\mathrm{TiO}_{2}, \mathrm{La}^{3+}$ ions on the surface of nano- $\mathrm{TiO}_{2}$ are oxidized and form a single layer of lanthanide oxide, which is difficult to detect by XRD. According to the solid physical band theory, in the nano- $\mathrm{TiO}_{2}$ crystal, the ionic radius of $\mathrm{Ti}^{4+}$ is $0.074 \mathrm{~nm}$, and the ionic radius of $\mathrm{Fe}^{3+}$ is $0.069 \mathrm{~nm}$. Thus, $\mathrm{Fe}^{3+}$ can easily spread into the nano- $\mathrm{TiO}_{2}$ lattice and replace $\mathrm{Ti}^{4+}$ in the nano- $\mathrm{TiO}_{2}$ lattice. The ionic sizes of $\mathrm{Fe}^{3+}$ and $\mathrm{Ti}^{4+}$ ions are different, leading to nano-scale $\mathrm{TiO}_{2}$ crystal lattice deformation. Upon $\mathrm{La}^{3+}$ doping onto nano- $\mathrm{TiO}_{2}, \mathrm{La}^{3+}$ replaces the lattice $\mathrm{Ti}^{4+}$. The ionic radius of $\mathrm{La}^{3+}$ is $0.115 \mathrm{~nm}$, which is larger than that of $\mathrm{Ti}^{4+}$. Thus, the substitution of $\mathrm{La}^{3+}$ for $\mathrm{Ti}^{4+}$ will cause distortion and inflation of the nano- $\mathrm{TiO}_{2}$ crystal lattice, which will improve the photocatalytic activity of the material.

The size of the nanoscale grain obtained using this formula, that is, the first particle size of oriented crystal growth, cannot reflect particle agglomeration. The calculation results are shown in Table 1.

The calculation results show that the average particle size of $\mathrm{Fe}^{3+} / \mathrm{La}^{3+}$ codoped nano- $\mathrm{TiO}_{2}$ was lower than that of pure $\mathrm{TiO}_{2}$. The particle size of $0.01 \% \mathrm{Fe}^{3+} / 0.6 \% \mathrm{La}^{3+}$-doped $\mathrm{TiO}_{2}$ was the smallest among those tested $(6.1 \mathrm{~nm})$. According to the results of photocatalytic degradation of methyl orange solution, the photocatalytic activity of $0.01 \% \mathrm{Fe}^{3+} / 0.6 \% \mathrm{La}^{3+}$ doped $\mathrm{TiO}_{2}$ was the best among the photocatalysts tested. The average grain size of tombarthite-doped $\mathrm{TiO}_{2}$ was smaller

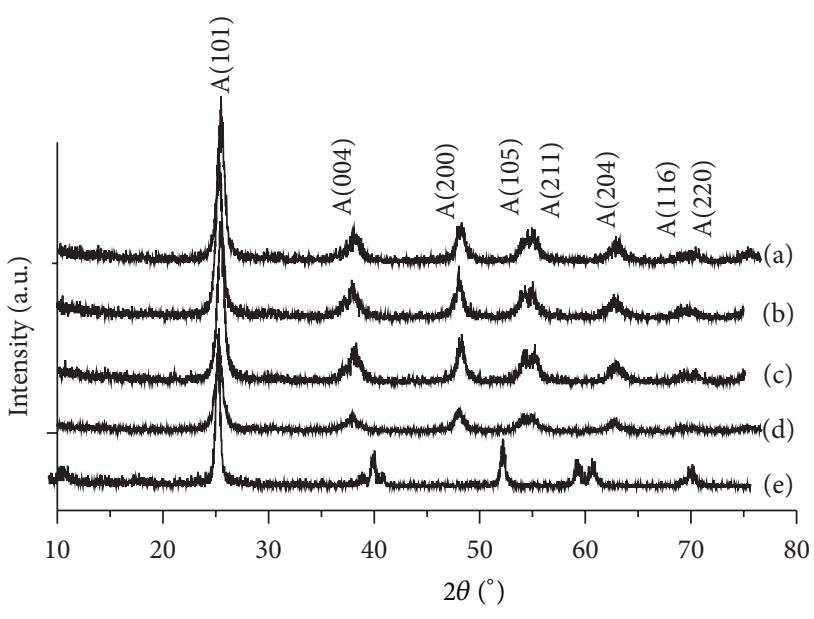

FIGURE 2: XRD spectra of the prepared nano- $\mathrm{TiO}_{2}$ photocatalysts, (a) $\mathrm{La}-\mathrm{TiO}_{2}$, (b) $0.01 \% \mathrm{Fe} / 1.0 \% \mathrm{La}-\mathrm{TiO}_{2}$, (c) $0.01 \% \mathrm{Fe} / 0.6 \% \mathrm{La}-\mathrm{TiO}{ }_{2}$, (d) $\mathrm{Fe}-\mathrm{TiO}_{2}$, and (e) $\mathrm{TiO}_{2}$.

TABLE 1: XRD analysis results (A: anatase).

\begin{tabular}{lcc}
\hline Temperature $\left({ }^{\circ} \mathrm{C}\right)$ & Particle size $(\mathrm{nm})$ & Crystal phase \\
\hline $500^{\circ} \mathrm{C}$ pure $\mathrm{TiO}_{2}$ & 20.0 & $100 \% \mathrm{~A}$ \\
$500^{\circ} \mathrm{C} \mathrm{Fe}-\mathrm{TiO}_{2}$ & 8.2 & $100 \% \mathrm{~A}$ \\
$500^{\circ} \mathrm{C} \mathrm{La}-\mathrm{TiO}_{2}$ & 7.4 & $100 \% \mathrm{~A}$ \\
$500^{\circ} \mathrm{C} 0.01 \% \mathrm{Fe} 0.6 \mathrm{La}-\mathrm{TiO}_{2}$ & 6.1 & $100 \% \mathrm{~A}$ \\
$500^{\circ} \mathrm{C} 0.01 \% \mathrm{Fe} / 1.0 \mathrm{La}-\mathrm{TiO}_{2}$ & 7.7 & $100 \% \mathrm{~A}$ \\
\hline
\end{tabular}

than that of pure $\mathrm{TiO}_{2}$, indicating that the mixture of tombarthite ions inhibited the growth of the nanocrystalline phase. The average grain size of nano- $\mathrm{TiO}_{2}$ codoped with tombarthite ions and transition metal ions was smaller, indicating that doping improved this inhibition.

Doping with metal ions will affect the phase transition temperature, grain size, and other parameters and cause lattice distortion. $\mathrm{Fe}^{3+}$ partly replaced lattice $\mathrm{Ti}^{4+}$, inevitably causing oxygen defects, and the existence of oxygen vacancies is thought to promote grain growth of the rutile phase. Therefore, $\mathrm{Fe}^{3+}$ doping has a beneficial effect on the transformation of nano- $\mathrm{TiO}_{2}$ from anatase to rutile type. Doping with $\mathrm{La}^{3+}$ can inhibit the transformation of $\mathrm{TiO}_{2}$ from anatase to rutile and thereby increase the content of the highly photocatalytic anatase phase, causing the grain size of nano$\mathrm{TiO}_{2}$ to decrease and thus the quantization effect to increase. Therefore, the synergistic effect of codoping with $\mathrm{Fe}^{3+}$ and $\mathrm{La}^{3+}$ makes the photocatalyst activity higher than the sum of the activities with single ion doping. According to Figure 2, upon doping with a small amount of $\mathrm{Fe}^{3+}$ and $\mathrm{La}^{3+}$, the diffraction peaks of nano- $\mathrm{TiO}_{2}$ shift towards the low angle direction, indicating that the diffraction peaks of $\mathrm{Fe}^{3+} / \mathrm{La}^{3+}$ codoped nano- $\mathrm{TiO}_{2}$ catalyst are wider than those of pure $\mathrm{TiO}_{2}$. Compared with pure nano- $\mathrm{TiO}_{2}$, the particle size of doped nano- $\mathrm{TiO}_{2}$ was reduced. This is because a certain amount $\mathrm{Fe}^{3+}$ and $\mathrm{La}^{3+}$ penetrates the nano- $\mathrm{TiO}_{2}$ crystal lattice, restricting the transfer and rearrangement of $\mathrm{Ti}$ and 

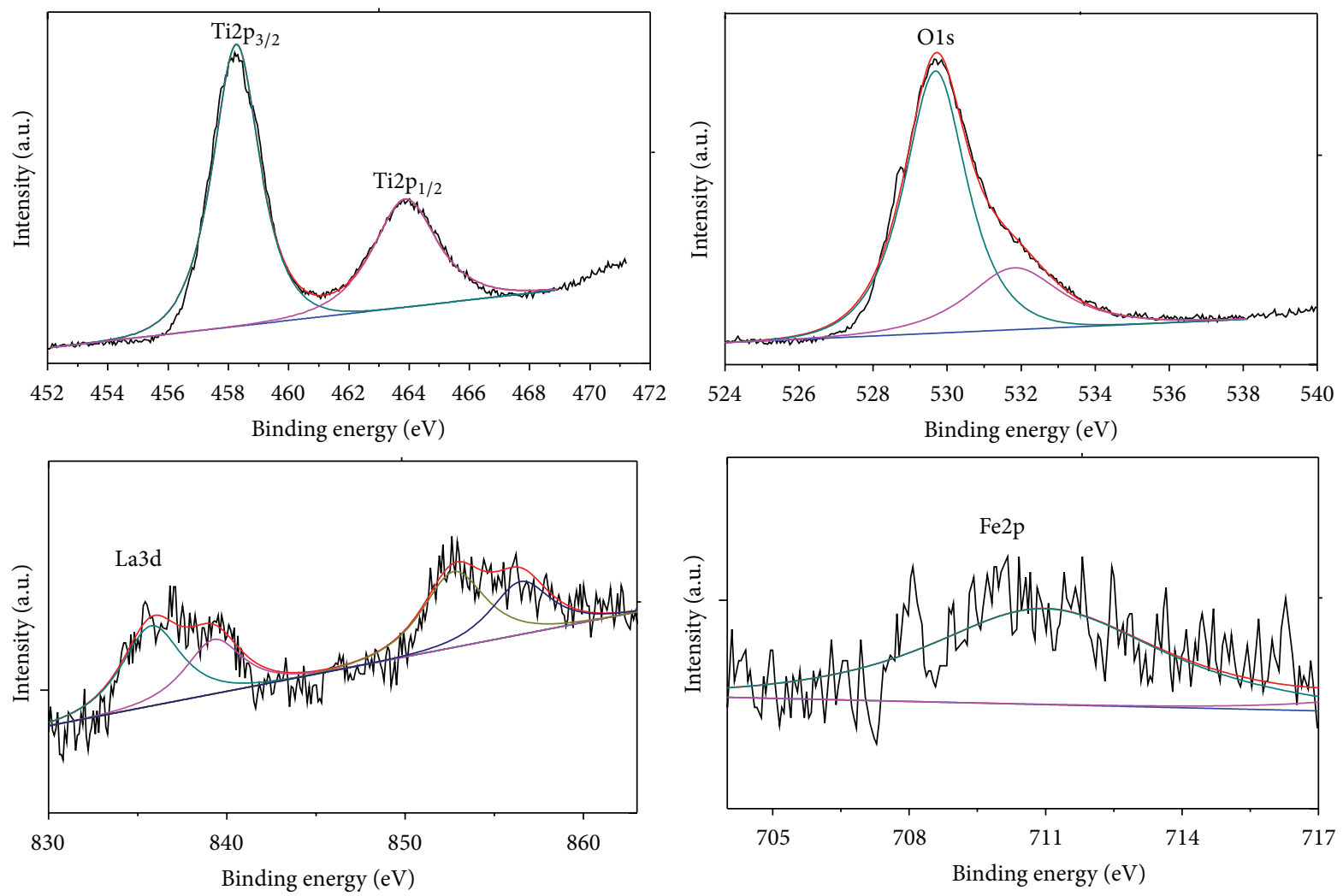

(a)
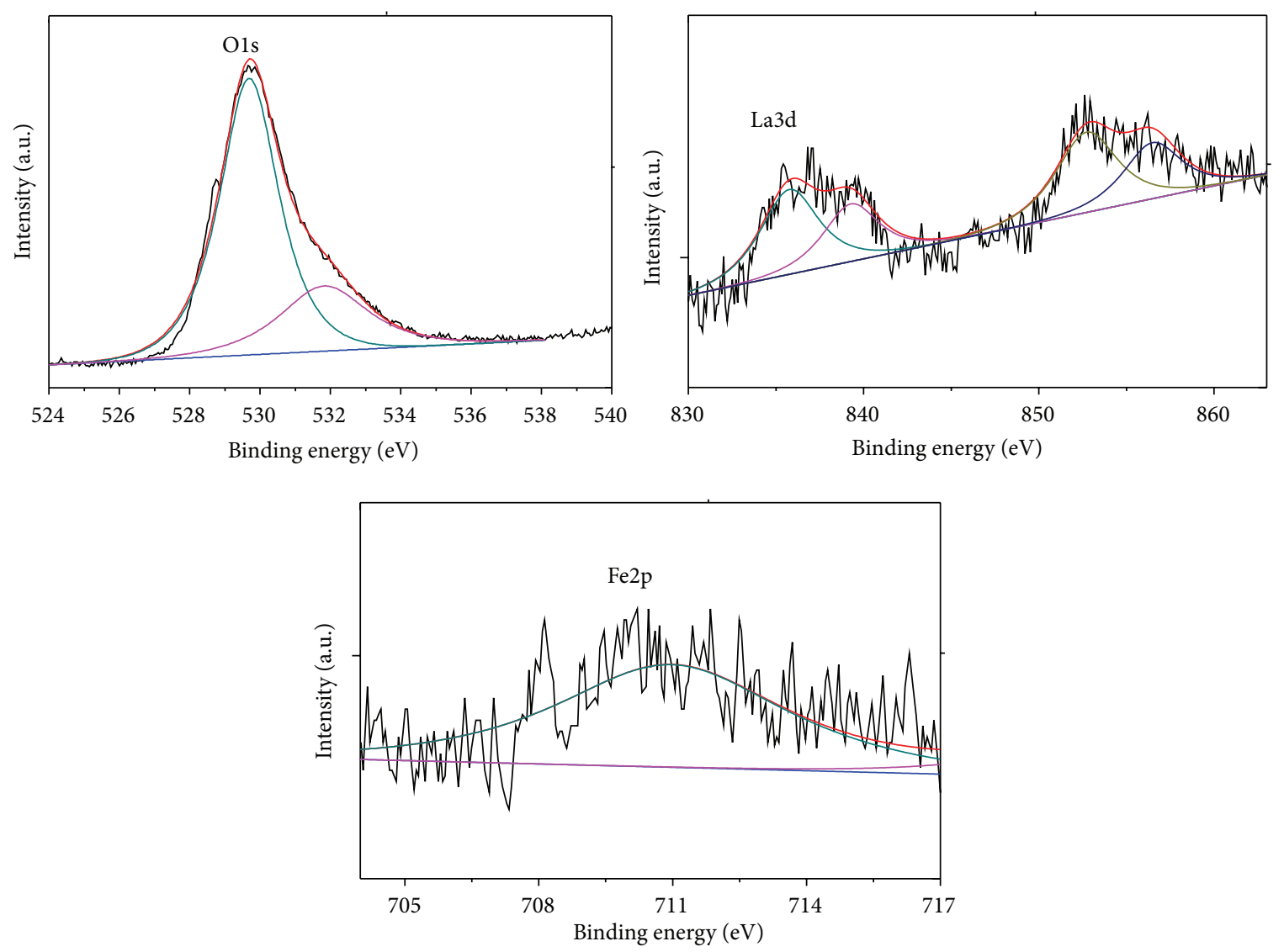

(b)

Figure 3: Continued. 

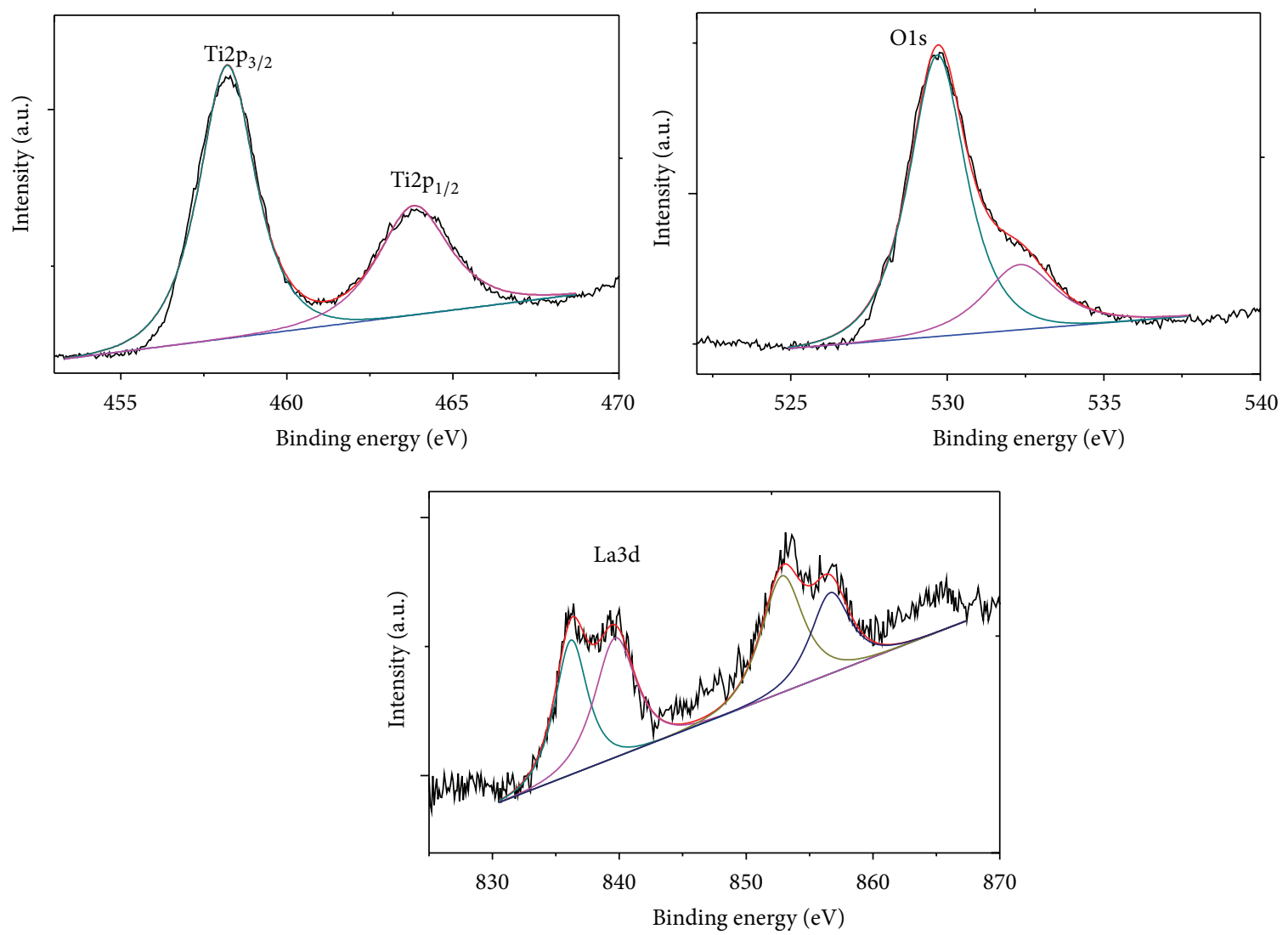

(c)
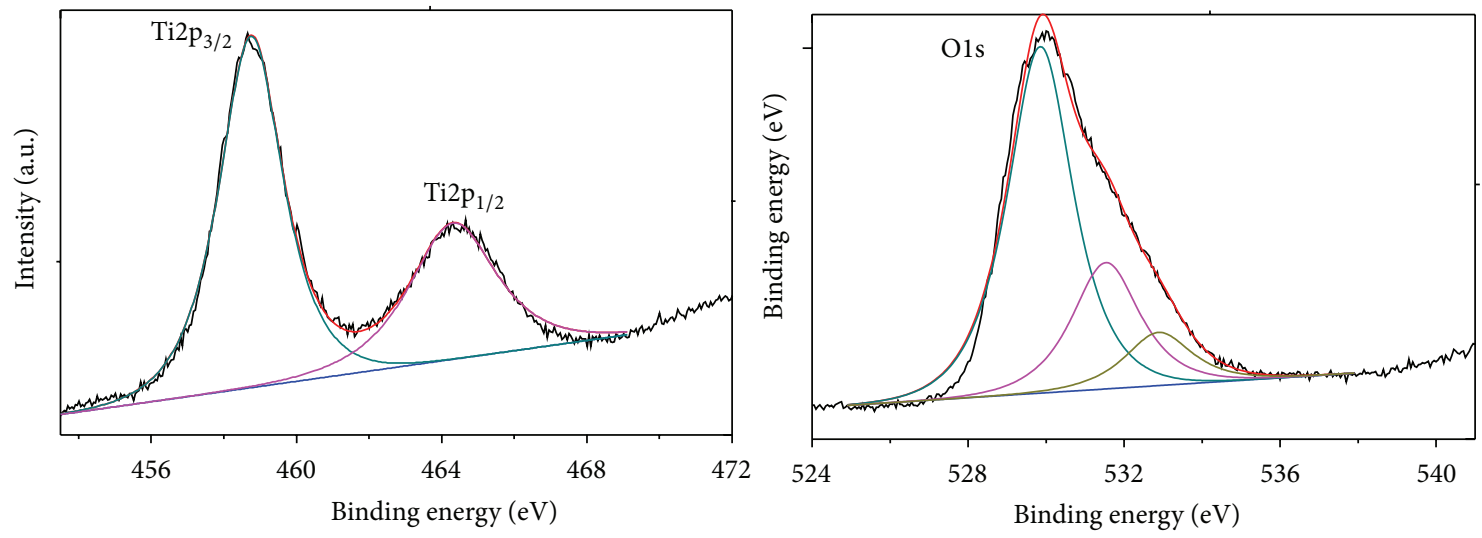

(d)

FIGURE 3: XPS spectra for different elements in (a) $0.01 \% \mathrm{Fe}^{3+} / 0.6 \% \mathrm{La}^{3+}$ codoped nano- $\mathrm{TiO}_{2}$, (b) $0.01 \% \mathrm{Fe}^{3+}$ doped $\mathrm{TiO}_{2}$, (c) $0.6 \% \mathrm{La}^{3+}$ doped $\mathrm{TiO}_{2}$, and (d) $\mathrm{TiO}_{2}$.

$\mathrm{O}$ ions, inhibiting the growth of nano- $\mathrm{TiO}_{2}$ crystals and decreasing the particle size.

3.2. Elemental Analysis of the Prepared $\mathrm{Nano}-\mathrm{TiO}_{2}$ Photocatalyst. Figures 3(a), 8(b), and 8(c) show the XPS spectra of different elements in $0.01 \% \mathrm{Fe}^{3+} / 0.6 \% \mathrm{La}^{3+}$ codoped nano$\mathrm{TiO}_{2}, 0.01 \% \mathrm{Fe}^{3+}$ doped $\mathrm{TiO}_{2}$, and $0.6 \% \mathrm{La}^{3+}$ doped $\mathrm{TiO}_{2}$, respectively. Figure 3(d) shows XPS spectrum of different elements in $\mathrm{TiO}_{2}$. According to the high-resolution XPS patterns of Ti2p in these four spectra, there are two characteristic peaks of the same type at $463 \mathrm{eV}$ and $458 \mathrm{eV}$. These two peaks correspond to the absorption peaks of $\mathrm{Ti}_{2} \mathrm{p}_{1 / 2}$ and $\mathrm{Ti} 2 \mathrm{p}_{2 / 3}$ in anatase type $\mathrm{TiO}_{2}$, respectively, indicating that elemental $\mathrm{Ti}$ exists in the form of $\mathrm{Ti}^{4+}$ and the titanium oxide bond is stable. In $\mathrm{Fe}^{3+}$ doped nano- $\mathrm{TiO}_{2}$, the combining capacities of Ti2 $\mathrm{p}_{2 / 3}$ and Ti2 $\mathrm{p}_{1 / 2}$ are $458.28 \mathrm{eV}$ and $463.90 \mathrm{eV}$, respectively. In $0.6 \% \mathrm{La}^{3+}$ doped nano- $\mathrm{TiO}_{2}$, the combining capacities of Ti2 $\mathrm{p}_{2 / 3}$ and Ti2 $\mathrm{p}_{1 / 2}$ are $458.20 \mathrm{eV}$ and $463.82 \mathrm{eV}$, 
respectively. In $0.01 \% \mathrm{Fe}^{3+} / 0.6 \% \mathrm{La}^{3+}$ doped nano- $\mathrm{TiO}_{2}$, the combining capacities of Ti2 $\mathrm{p}_{2 / 3}$ and Ti2 $\mathrm{p}_{1 / 2}$ are $458.25 \mathrm{eV}$ and $463.88 \mathrm{eV}$, respectively. The values of combining capacity of these samples are different from those of pure $\mathrm{TiO}_{2}$ (combining capacities of Ti2 $\mathrm{p}_{2 / 3}$ and Ti2 $\mathrm{p}_{1 / 2}$ equal to $458.74 \mathrm{eV}$ and $463.31 \mathrm{eV}$, resp.). This is due to doping with $\mathrm{Fe}^{3+}$ and $\mathrm{La}^{3+}$. In the $\mathrm{Fe}^{3+} / \mathrm{La}^{3+}$ codoped $\mathrm{TiO}_{2}$, these two peaks shift $0.5 \mathrm{eV}$ toward the higher energy direction, indicating that the effective positive charge of Ti was increased. Upon doping with elemental $\mathrm{Fe}$ and $\mathrm{La}$, on the surface or in the lattice of nano- $-\mathrm{TiO}_{2}$, electronic redistribution occurs and leads to a decrease in the Ti outer electron density, a reduction in the shielding effect, and an increase in the electron binding energy. These effects are beneficial for increasing photocatalytic activity. The binding energy difference between catalyst Ti2p and O1s is $71.3 \mathrm{eV}$, which indicates that $\mathrm{Ti}$ in the three prepared catalysts is in the tetravalent form $\left(\mathrm{TiO}_{2}\right)$.

According to Figures 3(a)-3(c), the peaks at 529.6$529.8 \mathrm{eV}$ in the O1s high-resolution XPS patterns are mostly related to $\mathrm{Ti}$, and the surface hydroxyl or oxygen in oxide defects is the key. Hydroxyl groups on the surface of the catalyst are considered to be an important factor affecting photocatalytic activity. A hydroxyl group on the nano- $\mathrm{TiO}_{2}$ catalyst surface can capture light and generate an $\cdot \mathrm{OH}$ free radical, which has strong oxidation ability. The $\cdot \mathrm{OH}$ free radical is the main strong oxidizer in the photocatalytic reaction. Therefore, as the hydroxyl content on the surface of nano$\mathrm{TiO}_{2}$ catalyst increases, the surface becomes more conducive to the generation of $\cdot \mathrm{OH}$ free radicals and the quantization efficiency is further improved, thereby effectively improving the catalytic activity of the nano- $\mathrm{TiO}_{2}$ catalyst.

According to Figures 3(a) and 8(b), in the Fe2p highresolution XPS patterns for $0.01 \% \mathrm{Fe}^{3+}$ doped nano- $\mathrm{TiO}_{2}$ and $0.01 \% \mathrm{Fe}^{3+} / 0.6 \% \mathrm{La}^{3+}$ doped nano- $\mathrm{TiO}_{2}, \mathrm{Fe} 2 \mathrm{p}$ peaks appear at $710.68 \mathrm{eV}$ and $710.98 \mathrm{eV}$. This is trivalent iron, indicating that iron doped on $\mathrm{TiO}_{2}$ is in the form of $\mathrm{Fe}_{2} \mathrm{O}_{3}$. In addition, as shown in Figure 3(c), no Fe2p peak appears in the $\mathrm{TiO}_{2}$ XPS spectrum, indicating that elemental $\mathrm{Fe}$ exists only in crystalline $\mathrm{Fe}^{3+} / \mathrm{La}^{3+}$ doped nano- $\mathrm{TiO}_{2}$. Elemental $\mathrm{Fe}$ in the three prepared catalysts is in the tetravalent form.

According to Figures 3(a) and 3(c), in the La3d highresolution XPS patterns of $0.6 \% \mathrm{La}^{3+}$ doped nano- $-\mathrm{TiO}_{2}$ and $0.01 \% \mathrm{Fe}^{3+} / 0.6 \% \mathrm{La}^{3+}$ doped nano- $-\mathrm{TiO}_{2}, \mathrm{La} 3 \mathrm{~d}$ peaks appear at $835.75 \mathrm{eV}$ and $836.20 \mathrm{eV}$. In Figure 3(d), no La3d peaks appear in the $\mathrm{TiO}_{2}$ XPS spectrum at these positions, confirming that elemental $\mathrm{La}$ was present only in $\mathrm{La}^{3+}$ doped nano- $-\mathrm{TiO}_{2}$ and $\mathrm{Fe}^{3+} / \mathrm{La}^{3+}$ codoped nano- $-\mathrm{TiO}_{2}$ powders. The difference in the binding energies of $\mathrm{La}^{3+}$ doped nano- $\mathrm{TiO}_{2}$ and $\mathrm{Fe}^{3+} / \mathrm{La}^{3+}$ codoped nano- $-\mathrm{TiO}_{2}$ is $0.5 \mathrm{eV}$. This suggests that $\mathrm{La}^{3+}$ doping changed the electronic distribution on the nano- $-\mathrm{TiO}_{2}$ surface or lattice, thus improving photocatalytic performance. In the La3d spectrum, two peaks appear for

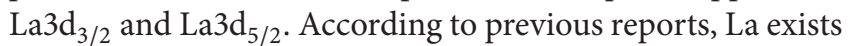
in the form of $\mathrm{La}_{2} \mathrm{O}_{3}[25,26]$. Thus, $\mathrm{La}^{3+}$ ions did not enter into the lattice of $\mathrm{TiO}_{2}$. This is because the ionic radius of $\mathrm{La}^{3+}$ ions is bigger than that of $\mathrm{Ti}^{4+}$ ions, and thus, $\mathrm{La}^{3+}$ ions cannot enter into the lattice of $\mathrm{TiO}_{2}$.
3.3. FS Analysis of the Prepared $\mathrm{Nano}-\mathrm{TiO}_{2}$ Photocatalyst. Figure 4 shows the fluorescence spectra of $\mathrm{TiO}_{2}$ and the three prepared nano- $\mathrm{TiO}_{2}$ photocatalysts. According to Figure 4(a)(A-D), the fluorescence spectra for $\mathrm{Fe}^{3+} / \mathrm{La}^{3+}$ codoped nano- $-\mathrm{TiO}_{2}$ and pure $\mathrm{TiO}_{2}$ have a fluorescence peak at $417 \mathrm{~nm}$. The intensity of this peak for $\mathrm{Fe}^{3+} / \mathrm{La}^{3+}$ codoped nano- $-\mathrm{TiO}_{2}$ is lower than that in the spectra for nano- $\mathrm{TiO}_{2}$ doped with either metal or pure $\mathrm{TiO}_{2}$. Combined with the experimental results for methyl orange solution decolorization, this decrease in fluorescence intensity indicates a reduced recombination rate of photo-produced electronhole pairs, and thus, an increased photocatalytic activity. The above results show that the improvement in visible light catalytic activity is due to the reduction of the light carrier recombination rate by doping.

Figure 4(b) shows the fluorescence spectra of nano- $\mathrm{TiO}_{2}$ doped with different amounts of $\mathrm{La}^{3+}$. Figure 4(c) shows the fluorescence spectra of nano- $\mathrm{TiO}_{2}$ doped with different amounts of $\mathrm{Fe}^{3+}$. Figure 4(d) shows the fluorescence spectra of nano- $\mathrm{TiO}_{2}$ doped with different amounts of $\mathrm{Fe}^{3+}$ and $\mathrm{La}^{3+}$. According to these spectra, $\mathrm{TiO}_{2}$ shows a strong peak at $417 \mathrm{~nm}$, and the position of this peak is not affected by doping of the nano- $\mathrm{TiO}_{2}$ with any amount of $\mathrm{Fe}^{3+}$ and/or $\mathrm{La}^{3+}$. The intensity of this peak is weaker in the spectra for $\mathrm{Fe}^{3+} / \mathrm{La}^{3+}$ codoped nano-TiO ${ }_{2}$. La and $\mathrm{Fe}$ exist in the form of $\mathrm{La}_{2} \mathrm{O}_{3}$ and $\mathrm{Fe}_{2} \mathrm{O}_{3}$, respectively, and these metal oxides can function as agents to capture photo-produced electrons. After capture of a photo-produced electron, it is difficult for the electron to recombine with a hole. Together with the results of the methyl orange decolorization experiments, these results showing that the fluorescence intensity of codoped samples is smaller indicate that their photocatalytic activity is better. Codoping with $\mathrm{Fe}^{3+}$ and $\mathrm{La}^{3+}$ reduces the recombination rate of photo-produced electron-hole pair and improves the quantum efficiency, thus leading to improvement in the photocatalytic efficiency.

3.4. UV-Vis Analysis. Figure 5(a) shows UV-Vis absorption spectra of nano- $\mathrm{TiO}_{2}$ doped with different amounts of $\mathrm{Fe}^{3+}$. Relative to the absorption spectra of pure $\mathrm{TiO}_{2}$, the absorption band edge of $\mathrm{Fe}^{3+}$ doped nano- $\mathrm{TiO}_{2}$ shows an obvious red-shift. The obviously enhanced absorption strength in the visible area is beneficial for improving the utilization of sunlight and the photocatalytic efficiency. The main reason for this improvement is that the radius of $\mathrm{Fe}^{3+}(0.064 \mathrm{~nm})$ is similar to that of $\mathrm{Ti}^{4+}(0.068 \mathrm{~nm})$, and thus, $\mathrm{Fe}^{3+}$ can replace some $\mathrm{Ti}^{4+}$ in the lattice and create lattice defects. Impurity level formed in nano- $\mathrm{TiO}_{2}$ band gap, and the energy of semiconductor optical electronic transiting to guide reduced, smaller energy photoproduction electronic can also transit, so the spectrum redshift, light response range extended.

Figure 5(b) shows the UV-Vis absorption spectra of nano$\mathrm{TiO}_{2}$ doped with different amounts of $\mathrm{La}^{3+}$. The absorption sideband of $\mathrm{La}^{3+}$ doped nano- $-\mathrm{TiO}_{2}$ moved towards the longer wavelengths, and the absorption rate of light increased. This is because the radius of $\mathrm{La}^{3+}$ is $0.115 \mathrm{~nm}$, which is larger than that of $\mathrm{Ti}^{4+}(0.068 \mathrm{~nm})$. Thus, $\mathrm{La}^{3+}$ has difficultly entering the 


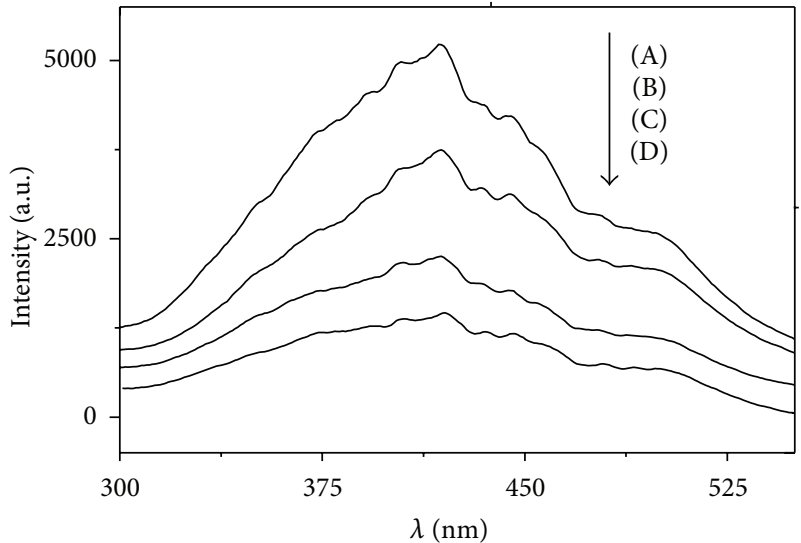

(a)

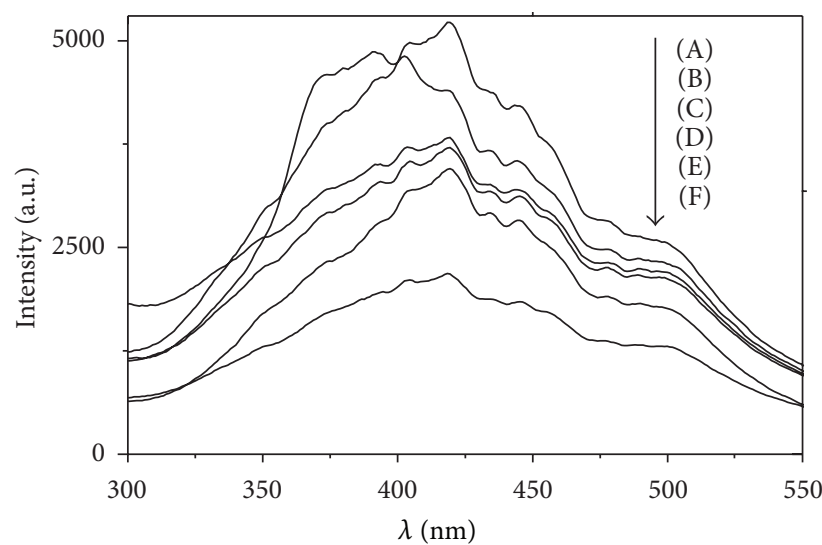

(c)

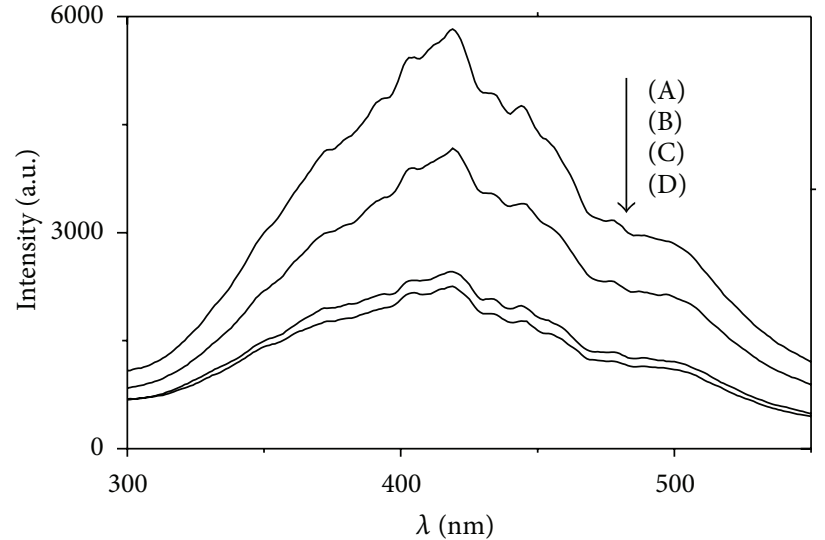

(b)

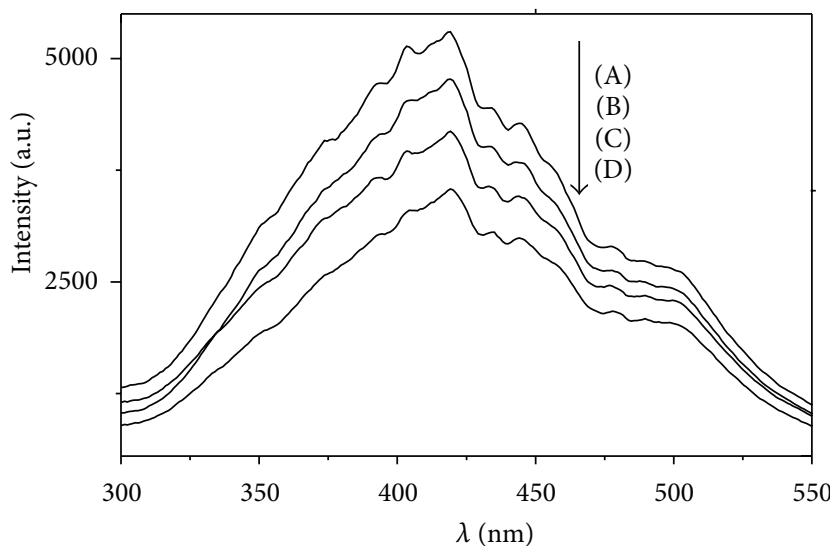

(d)

Figure 4: (a) Fluorescence spectra of (A) $\mathrm{TiO}_{2}$, (B) $0.01 \% \mathrm{Fe}^{3+}$ doped nano- $\mathrm{TiO}_{2}$, (C) $0.6 \% \mathrm{La}^{3+}$ doped nano-TiO , and (D) $0.01 \% \mathrm{Fe}^{3+} / 0.6 \%$ $\mathrm{La}^{3+}$ codoped nano- $\mathrm{TiO}_{2}$; (b) fluorescence spectra of (A) $1.5 \% \mathrm{La}^{3+}$, (B) $1.0 \% \mathrm{La}^{3+}$, (C) $0.3 \% \mathrm{La}^{3+}$, and (D) $0.6 \% \mathrm{La}^{3+}$ doped nano-TiO, (c) fluorescence spectra of (A) $0.005 \% \mathrm{Fe}^{3+}$, (B) $0.1 \% \mathrm{Fe}^{3+}$, (C) $0.05 \% \mathrm{Fe}^{3+}$, (D) $0.2 \% \mathrm{Fe}^{3+}$, (E) $0.15 \% \mathrm{Fe}^{3+}$, and (F) $0.01 \% \mathrm{Fe}^{3+}$ doped nano-TiO ; (d) fluorescence spectra of nano- $\mathrm{TiO}_{2}$ codoped with (A) $0.15 \% \mathrm{Fe}^{3+}$ and $0.6 \% \mathrm{La}^{3+}$, (B) $0.01 \% \mathrm{Fe}^{3+}$ and $1.0 \% \mathrm{La}^{3+}$, (C) $0.01 \% \mathrm{Fe} e^{3+}$ and $0.5 \%$ $\mathrm{La}^{3+}$, and (D) $0.01 \% \mathrm{Fe}^{3+}$ and $0.6 \% \mathrm{La}^{3+}$.

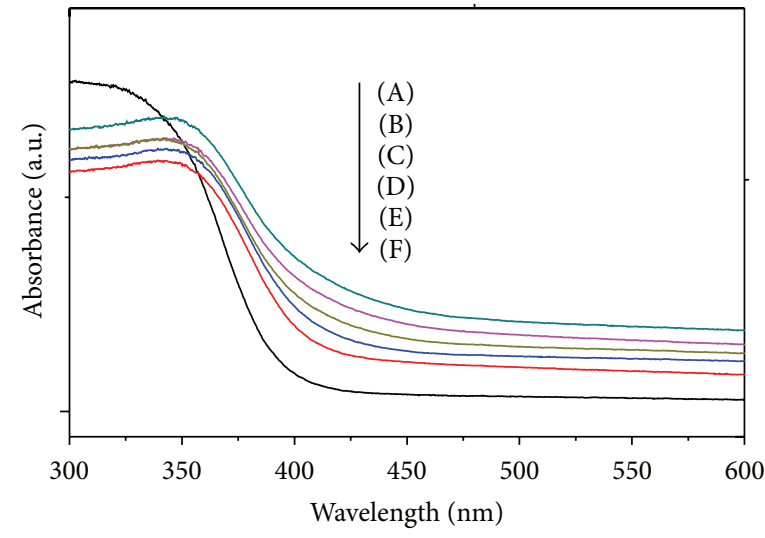

(a)

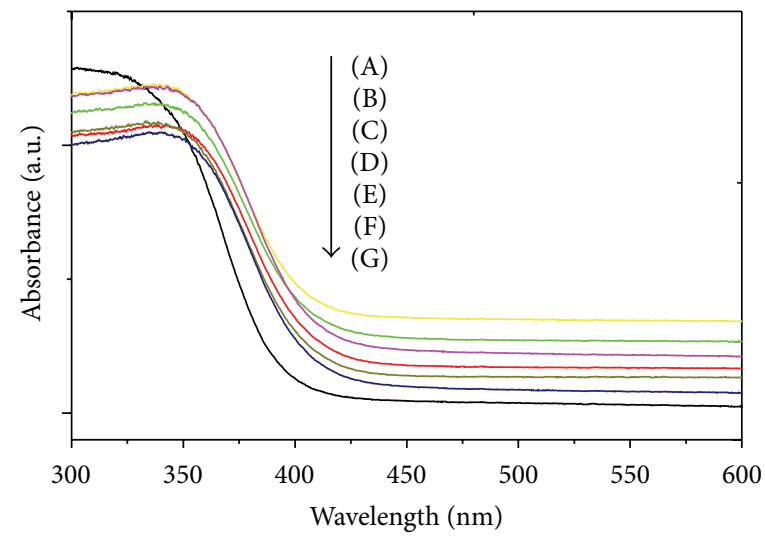

(b)

Figure 5: (a) UV-Vis absorption spectra of nano- $\mathrm{TiO}_{2}$ doped with (A) $0.1 \% \mathrm{Fe}^{3+}$, (B) $0.15 \% \mathrm{Fe}^{3+}$, (C) $0.2 \% \mathrm{Fe}^{3+}$, (D) $0.05 \% \mathrm{Fe}^{3+}$, and (E) $0.01 \%$ $\mathrm{Fe}^{3+}$, and (F) pure $\mathrm{TiO}_{2}$; (b) UV-Vis absorption spectra of nano- $\mathrm{TiO}_{2}$ doped with (A) $0.6 \% \mathrm{La}^{3+}$, (B) $0.5 \% \mathrm{La}^{3+}$, (C) $0.7 \% \mathrm{La}^{3+}$, (D) $0.3 \% \mathrm{La}^{3+}$, (E) $1.0 \% \mathrm{La}^{3+}$, (F) $1.5 \% \mathrm{La}^{3+}$, and (G) pure $\mathrm{TiO}_{2}$. 


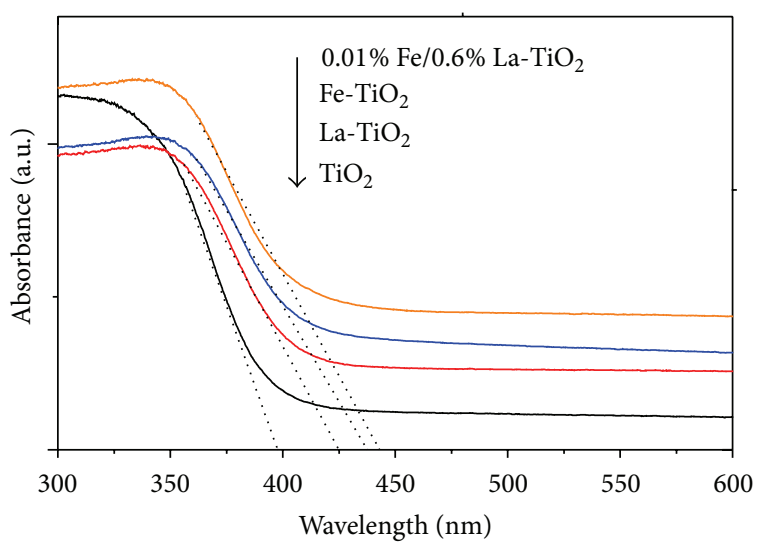

Figure 6: UV-Vis absorption spectra for nano- $\mathrm{TiO}_{2}$.

lattice of nano- $-\mathrm{TiO}_{2}$. When the quantity of doped La was very small, $\mathrm{La}$ covered the surface of nano- $\mathrm{TiO}_{2}$ mainly in its oxide form, hindering grain growth. This led to the particles of La-doped nano- $\mathrm{TiO}_{2}$ being smaller than those of nondoped nano- $-\mathrm{TiO}_{2}$. The tombarthite elements covering the surface of nano- $\mathrm{TiO}_{2}$ particles can absorb light over a wide range and transfer the energy to the nano- $\mathrm{TiO}_{2}$, thus improving the photocatalytic reactivity.

Figure 6 shows the UV-Vis absorption spectra for singleand codoped nano- $\mathrm{TiO}_{2}$ photocatalysts. The absorption bands for these nano- $\mathrm{TiO}_{2}$ catalysts shifted to the visible light region at varying degrees. For catalyst doped with $\mathrm{La}^{3+}$ and $\mathrm{Fe}^{3+}$ individually, the absorption edge moved $35 \mathrm{~nm}$ and $41 \mathrm{~nm}$ toward the visible light region, respectively. That for nano- $\mathrm{TiO}_{2}$ photocatalyst codoped with $0.01 \% \mathrm{Fe}^{3+}$ and $0.6 \% \mathrm{La}^{3+}$ moved $49 \mathrm{~nm}$ toward the visible light region. Therefore, the absorption sideband of Fe/La codoped nano$\mathrm{TiO}_{2}$ red-shifted more than that for the $\mathrm{Fe}^{3+}$ or $\mathrm{La}^{3+}$ singledoped nano- $\mathrm{TiO}_{2}$, and the absorption of visible light by the codoped catalyst is stronger than that by the singledoped catalysts. This indicated that the codoping with both elements has a synergistic effect. The main reasons are as follows: the $3 \mathrm{~d}$ orbital of $\mathrm{Fe}^{3+}$ is above the valence band of nano- $-\mathrm{TiO}_{2}$. Electrons on the $3 \mathrm{~d}$ orbital can absorb $415 \mathrm{~nm}$ visible light and transit it to nano- $-\mathrm{TiO}_{2}$ to create $\mathrm{Fe}^{4+}$, and thus, $\mathrm{Fe}^{3+}$ acts as an electron trap. The vacant $5 \mathrm{~d}$ orbital of $\mathrm{La}^{3+}$ serves as a good electron transfer orbital. This orbital can be used to transfer the photo-produced electrons in the $\mathrm{TiO}_{2}$ photocatalytic reaction, and thus, $\mathrm{La}^{3+}$ also acts as an electron trap. Therefore, codoping with $\mathrm{Fe}^{3+}$ and $\mathrm{La}^{3+}$ inhibited recombination of photo-produced electrons and holes, and thereby improved the quantum efficiency of photoproduction.

\subsection{Influence of Doping Amount on the Photocatalytic Activity of $\mathrm{Nano}-\mathrm{TiO}_{2}$}

3.5.1. Influence of Doping with $\mathrm{Fe}^{3+}$ or $\mathrm{La}^{3+}$ on the Photocatalytic Activity of $\mathrm{Nano}^{-\mathrm{TiO}_{2}}$. Figure 7(a) demonstrates the influence of $\mathrm{Fe}^{3+}$ doping concentration on the photocatalytic activity of nano- $\mathrm{TiO}_{2}$. According to Figure $7(\mathrm{a})$, the optimum doping amount of $\mathrm{Fe}^{3+}$ is $0.01 \%$, which gives methyl orange decolorization rates of $93.5 \%$ with $3 \mathrm{~h}$ of UV illumination (versus $56.88 \%$ for pure $\mathrm{TiO}_{2}$ ) and $29.8 \%$ with $5 \mathrm{~h}$ of visible light illumination (versus $4.2 \%$ for pure $\mathrm{TiO}_{2}$ ). Doping with $\mathrm{Fe}^{3+}$ causes the nano- $\mathrm{TiO}_{2}$ to not only be able to capture electrons, but also to capture holes and the carrier is easily released. Thus, doping with $\mathrm{Fe}^{3+}$ can increase the photocatalytic activity of the nano- $\mathrm{TiO}_{2}$ catalyst. Doping with a small amount of $\mathrm{Fe}^{3+}$ can reduce the recombination rate of electrons and holes and enhance the photocatalytic activity of nano- $\mathrm{TiO}_{2}$ in the visible region, by improving the visible light utilization efficiency. At a low doping concentration, $\mathrm{Fe}^{3+}$ can play a dual role as an electron and a hole trap, and thereby improve the photocatalytic activity of the catalyst. At a high doping concentration, $\mathrm{Fe}^{3+}$ can reduce the quantum efficiency of photo-produced electrons and holes, leading to a decrease in the photocatalytic activity of the catalyst. This also can explain the influence of the doping amount on the photocatalytic activity via the process of capturing electrons and holes crossing the barrier. The recombination rate depends on the distance, $R$, of separation between the electron and hole [27]:

$$
K_{\text {composite }} \infty \exp \left(-\frac{2 R}{\alpha_{0}}\right),
$$

where $K_{\text {composite }}$ is the recombination rate constant, $\alpha_{0}$ is the capture carrier hydrogen-like wave equation, and $R$ is the distance of separation between the electron and hole.

According to the formula above, when the doping concentration is less than the optimum value, the semiconductor does not have enough traps to catch carriers. When the doping concentration is larger than the optimum value, due to the reduction in the average distance between the electrons and traps, the recombination rate $K$ grows exponentially as the doping concentration is increased. Thus, use of the optimum doping amount of transition metal ions is critical.

Figure 7(b) shows the influence of $\mathrm{La}^{3+}$ doping concentration on the photocatalytic activity of nano- $\mathrm{TiO}_{2}$. As shown in Figure 7(b), doping with tombarthite element $\mathrm{La}^{3+}$ improved the photocatalytic activity of nano- $\mathrm{TiO}_{2}$. The methyl orange degradation rate under visible light illumination is greatly improved by La doping. The methyl orange decolorization rate increased as the doping amount of $\mathrm{La}^{3+}$ increased. The highest photocatalytic activity was observed for a doping concentration of $\mathrm{La}^{3+}$ of $0.6 \%$. The methyl orange decolorization rate was $88.1 \%$ with $3 \mathrm{~h}$ of UV irradiation (pure $\mathrm{TiO}_{2}$ ) and $27.4 \%$ with $5 \mathrm{~h}$ of visible light irradiation (versus $4.2 \%$ for pure $\mathrm{TiO}_{2}$ ). With greater doping amounts, the photocatalytic activity did not continue to increase, but instead decreased. Doping with La ions increased catalytic activity, because tombarthite elements can produce electron configuration, polycrystalline type, and thermal stability. Doping with the appropriate amount of a tombarthite element has a positive role in improving the crystal type and photocatalytic properties of nano- $-\mathrm{TiO}_{2}$. Because the $\mathrm{La}^{3+}$ radius is $0.106 \mathrm{~nm}$, which is different from that of $\mathrm{Ti}^{4+}(0.068 \mathrm{~nm})$, doping with La ions caused an increase in oxygen vacancy and defects on the 


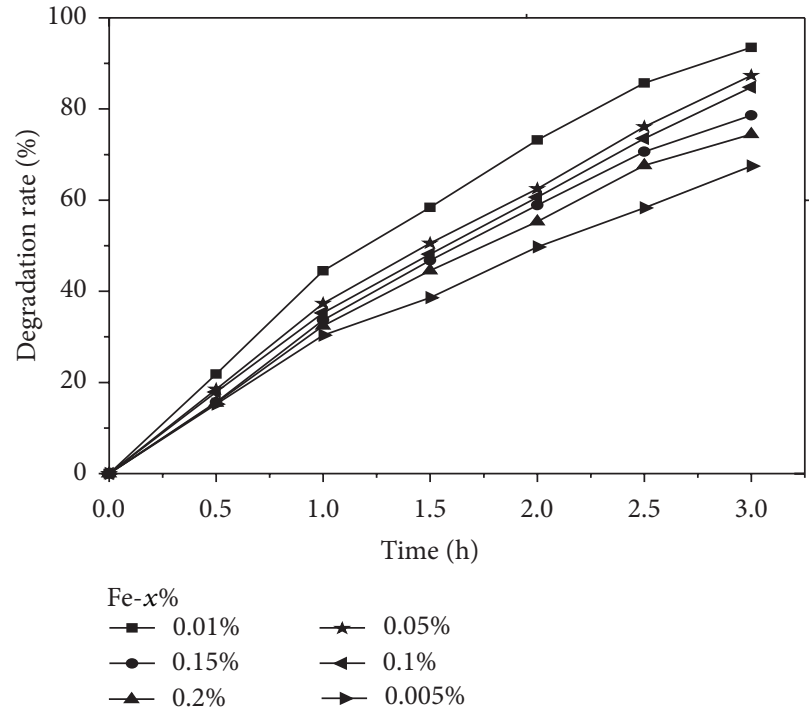

(A)

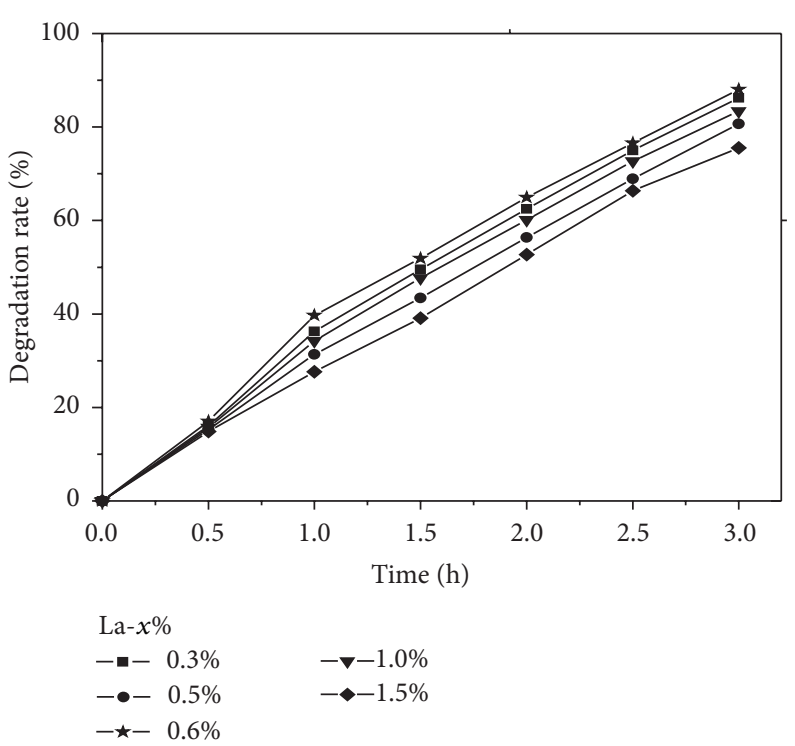

(A)

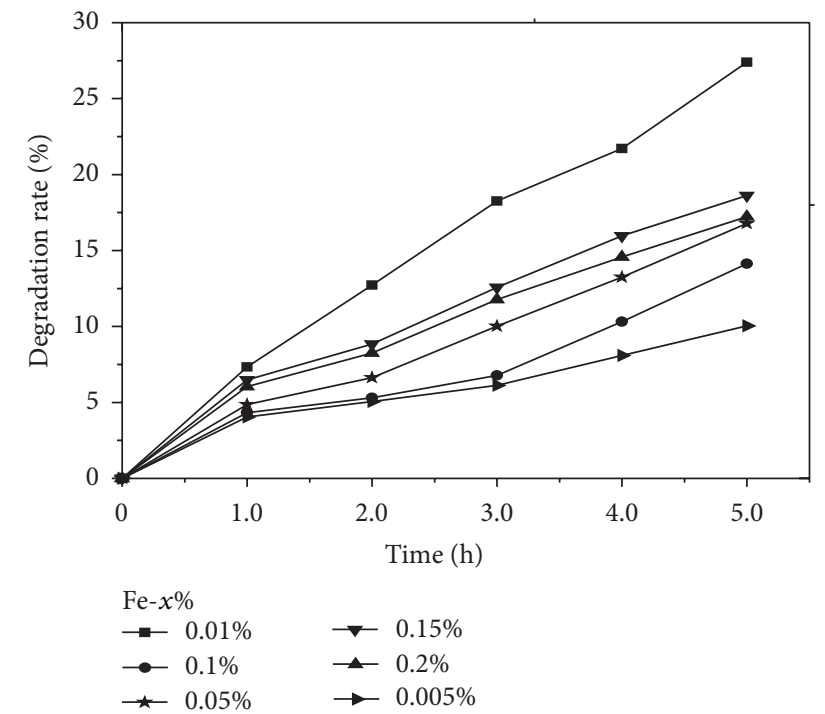

(B)

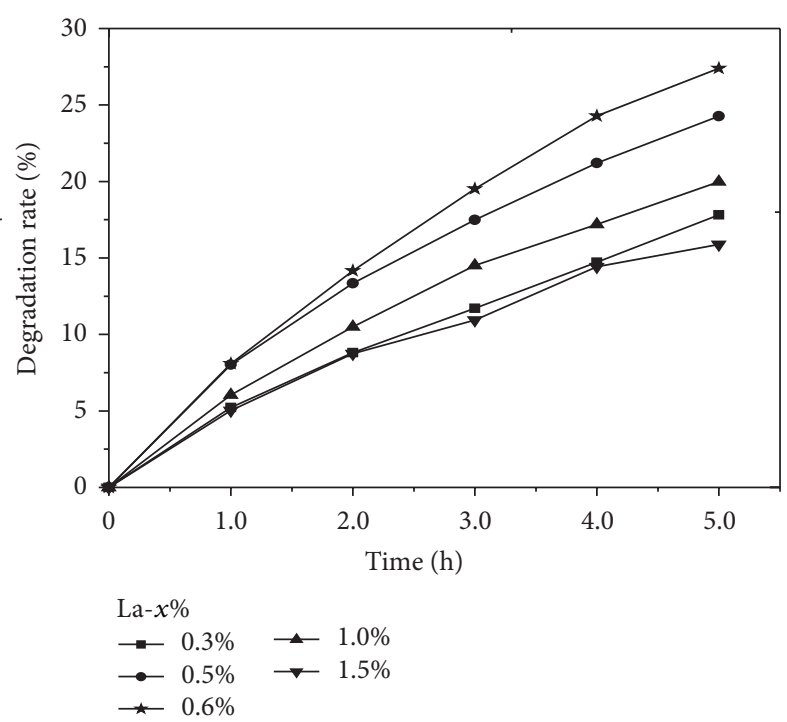

(B)

(b)

FIGURE 7: (a) Influence of $\mathrm{Fe}^{3+}$ doping concentration on photocatalytic activity of $\mathrm{TiO}_{2}$, (A) UV irradiation, (B) visible light irradiation; (b) influence of $\mathrm{La}^{3+}$ doping on the photocatalytic activity of nano- $\mathrm{TiO}_{2}$, (A) UV irradiation, (B) visible light irradiation.

surface of the nano- $\mathrm{TiO}_{2}$, effectively inhibiting the nano- $\mathrm{TiO}_{2}$ photo-production of electron-hole pairs, thereby improving the photocatalytic activity. However, too much tombarthite element also may cause a free electron transfer center to become a free electron recombination center and increase the photo-production of electron-hole pairs, thus reducing the photocatalytic activity.

The f orbital of tombarthite elements can have a coordination effect with the degradation substrate, and doping with a certain amount of La ions can effectively separate the nano$\mathrm{TiO}_{2}$ photo-produced electrons and holes, generating many active groups with strong oxidizing ability involved in the photocatalytic oxidation reduction reaction, thereby improving the photocatalytic activity of the catalyst. However, when the doping amount exceeds a certain concentration, too much tombarthite metal ion deposition on the surface of nano$\mathrm{TiO}_{2}$ hinders electron and hole transfer from the surface of the catalyst. Thus, tombarthite metal ions on the surface of the nano- $\mathrm{TiO}_{2}$ become charge carrier recombination centers, resulting in a decrease in catalytic activity.

3.6. The Influence of $\mathrm{Fe}^{3+} / \mathrm{La}^{3+}$ Codoping on $\mathrm{Nano}-\mathrm{TiO}_{2}$ Photocatalytic Activity. Figure 8 shows the influence of 


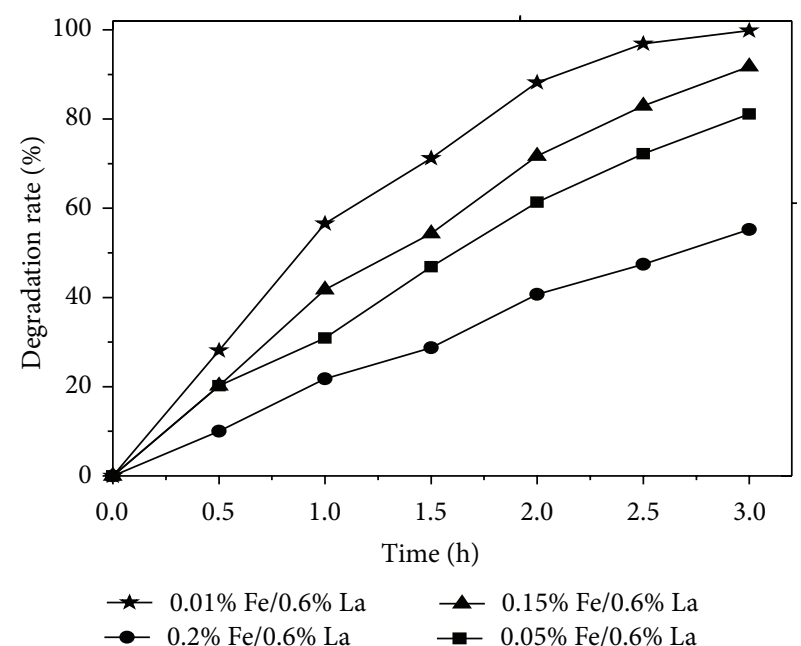

(a)

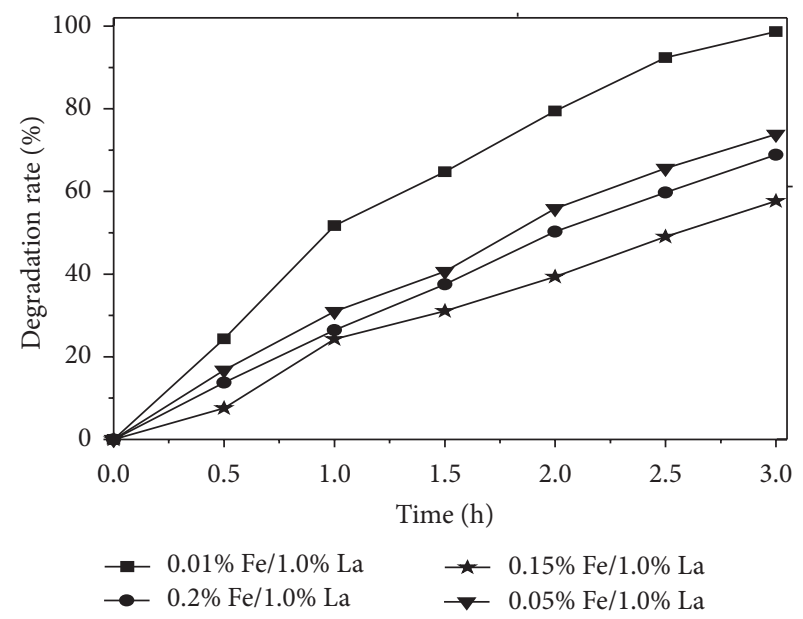

(c)

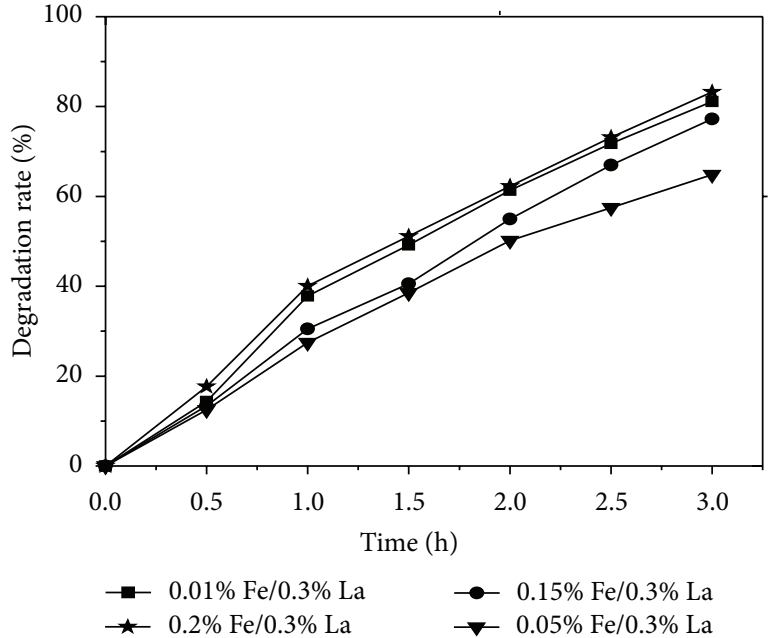

(b)

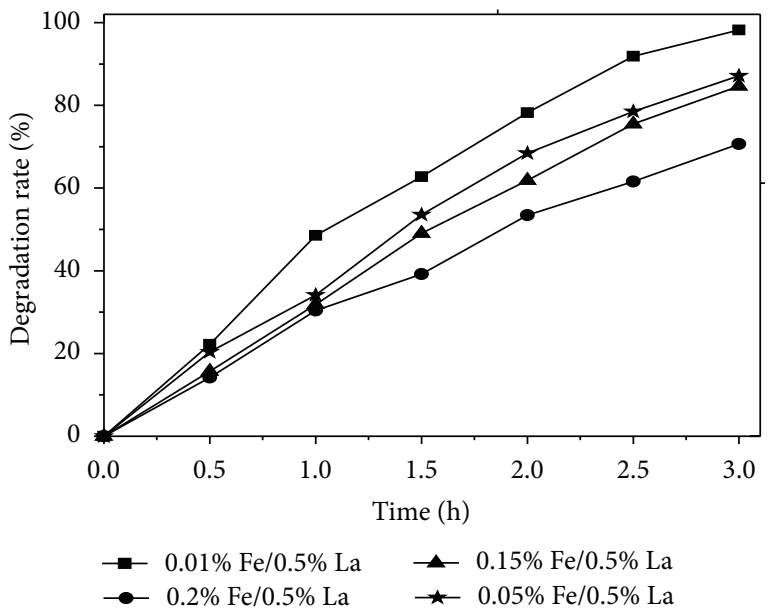

(d)

FIGURE 8: Effect of $\mathrm{Fe} / \mathrm{La}$ codoping on the photocatalytic activity of nano- $\mathrm{TiO}_{2}$ under UV light irradiation.

$\mathrm{Fe}^{3+} / \mathrm{La}^{3+}$ codoping on the photocatalytic activity of nano$\mathrm{TiO}_{2}$ under UV illumination, and Figure 9(a) shows the effect of $\mathrm{Fe}^{3+} / \mathrm{La}^{3+}$ codoping on the photocatalytic activity of nano$\mathrm{TiO}_{2}$ under visible light illumination. According to the results shown in these figures, the catalytic activity of codoped nano$\mathrm{TiO}_{2}$ is higher than that of catalyst doped with either $\mathrm{Fe}^{3+}$ or $\mathrm{La}^{3+}$. The $0.01 \% \mathrm{Fe}^{3+}$ and $0.6 \% \mathrm{La}^{3+}$ codoped nano-TiO possessed the highest photocatalytic activity. After $3 \mathrm{~h}$ of UV irradiation, the decolorization rate of methyl orange for $0.01 \%$ $\mathrm{Fe}^{3+}$ and $0.6 \% \mathrm{La}^{3+}$ codoped nano- $\mathrm{TiO}_{2}$ was $99.8 \%$. After $5 \mathrm{~h}$ of visible light irradiation, the decolorization rate of methyl orange for $0.01 \% \mathrm{Fe}^{3+}$ and $0.6 \% \mathrm{La}^{3+}$ codoped nano- $\mathrm{TiO}_{2}$ was $40.7 \%$. Both of these rates are greatly improved over those achieved by pure $\mathrm{TiO}_{2}$. Doping with transition metal $\mathrm{Fe}^{3+}$ ions alone did not hinder the modification of tombarthite ions, but worked together with tombarthite $\mathrm{La}^{3+}$ ions to further improve the activity of the photocatalyst.

The experimental results show that there are optimum doping amounts for both $\mathrm{Fe}^{3+}$ and $\mathrm{La}^{3+}$. A high concentration of doping ions can reduce the photocatalytic activity. Under the conditions of high concentrations, neither $\mathrm{Fe}^{3+}$ nor $\mathrm{La}^{3+}$ can effectively penetrate the crystal lattice of nano- $\mathrm{TiO}_{2}$, and therefore, these ions gather on the surface of crystals. An excessive of doping ions can catch large numbers of electrons and holes, reduce the quantum efficiency, and reduce the activity of catalysts. For low doping concentration, an increase in the doping ion concentration can improve the optical carrier separation effect. Therefore, because the thickness of the space between electrons and the surface of nano- $\mathrm{TiO}_{2}$ decreases with an increasing amount of doping tombarthite element, when the optimum concentration of doping metal is reached, the distance between the electrons and the surface is equal to the penetration depth of incident light into the solid and photoproduction of electrons and holes is achieved by optimal light irradiation, benefiting the photocatalytic reaction. The combined effects of $\mathrm{Fe}^{3+}$ and $\mathrm{La}^{3+}$ upon codoping of nano- $\mathrm{TiO}_{2}$ photocatalyst promoted the optimum separation of photoproduced electrons and 


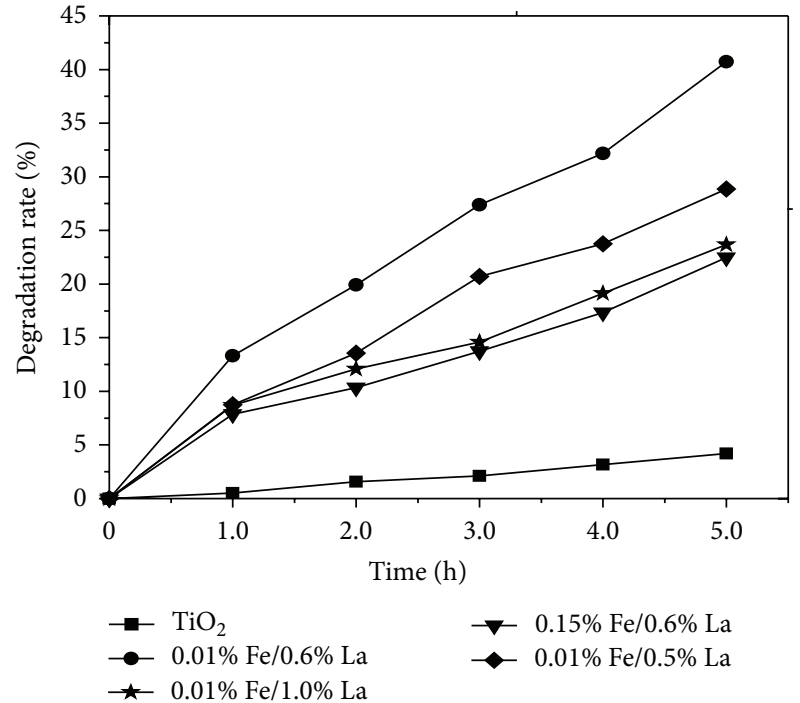

(a)

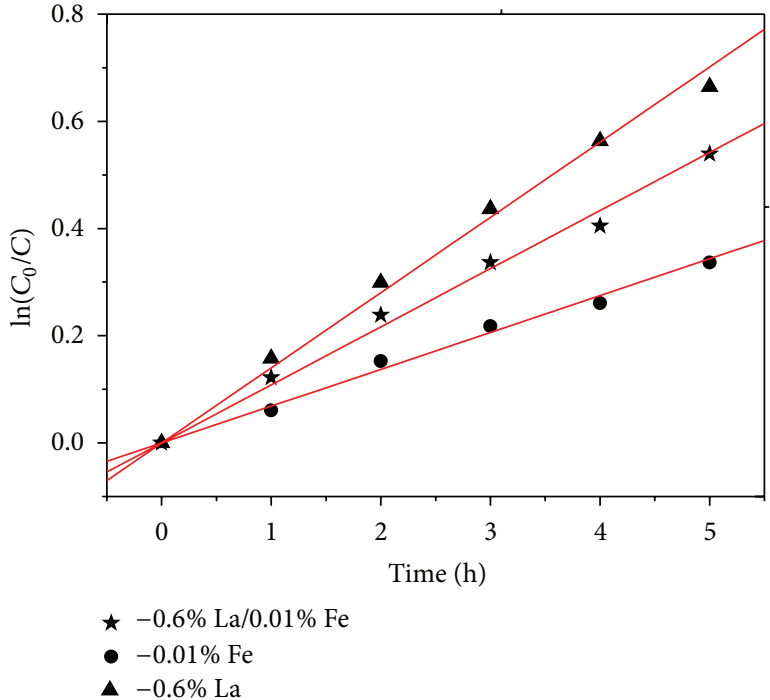

(b)

FIgURE 9: (a) Effect of Fe/La codoping on the photocatalytic activity of nano- $\mathrm{TiO}_{2}$ under visible light irradiation; (b) relationship between $\ln \left(C_{0} / C\right)$ and photocatalysis time for the different doped nano- $\mathrm{TiO}_{2}$ catalysts.

holes and thus improved the photocatalytic activity of the photocatalyst.

\subsection{Kinetics of the Photocatalytic Activity of Codoped Nano-} $\mathrm{TiO}_{2}$. For a heterogeneous photocatalytic system, such as the nano- $\mathrm{TiO}_{2}$ photocatalytic system, the reaction rate of photocatalytic oxidation can be described by the LangmuirHinshelwood dynamics equation as follows [28]:

$$
-\frac{d C}{d t}=\frac{k K C}{1+K C}
$$

where $C$ is the concentration of reactant, $k$ is the activity constant, and $K$ is the adsorption equilibrium constant of the reaction. Integration of (3) gives

$$
t=\frac{1}{K k} \ln \frac{C_{0}}{C}+\frac{1}{k}\left(C_{0}-C\right) .
$$

When the concentration $C$ is small, (4) can be transformed into

$$
\ln \frac{C_{0}}{C}=k^{\prime} t+A,
$$

where $k^{\prime}$ is the apparent rate constant and $A$ is a constant.

The kinetics for the degradation of methyl orange by the different prepared nano- $\mathrm{TiO}_{2}$ photocatalysts were investigated in the present study. The relationship between $\ln \left(C_{0} / C\right)$ $\left(C_{0}\right.$ is the initial concentration and $C$ is the concentration at time $t$ ) and photocatalysis time $t$ is shown in Figure 9(b). The fitting of the data for the photocatalytic degradation of methyl orange with a first-order kinetic curve is shown in Table 2.

According to Table 2, the $P$ value for the fitted straight line is far less than 0.01 , indicating that $\ln \left(C_{0} / C\right)$ and $t$ are significantly linearly correlated. As shown in Figure 9, under visible light irradiation, the degradation of methyl orange by different doped nano- $\mathrm{TiO}_{2}$ catalysts is well described by first-order reaction kinetics. The high correlation coefficients indicate that this model can be used to describe this photodegradation reaction.

\section{Conclusions}

In the present study, nano- $\mathrm{TiO}_{2}$ powder photocatalyst was prepared and modified via a sol-gel method by doping with either $\mathrm{Fe}^{3+}$ or $\mathrm{La}^{3+}$ individually or codoping with both $\mathrm{Fe}^{3+}$ and $\mathrm{La}^{3+}$. Codoping of nano- $\mathrm{TiO}_{2}$ photocatalysts with both $\mathrm{Fe}^{3+}$ and $\mathrm{La}^{3+}$ resulted in better catalytic performance than that achieved by doping with either $\mathrm{Fe}^{3+}$ or $\mathrm{La}^{3+}$, as well as better inhibition of nanocrystal growth and better refinement of grain size. Doping with tombarthite ions can effectively inhibit the shift of nano- $\mathrm{TiO}_{2}$ from anatase to rutile. $\mathrm{La}^{3+}$ doping changed the nano- $\mathrm{TiO}_{2}$ surface or lattice electron distribution. The sol-gel method can be used to effectively dope the lattice of nano- $\mathrm{TiO}_{2}$ with $\mathrm{Fe}^{3+}$ and $\mathrm{La}^{3+}$. Compared with catalyst doped with only $\mathrm{Fe}^{3+}$ or $\mathrm{La}^{3+}$, the light absorption intensity of $\mathrm{Fe}^{3+} / \mathrm{La}^{3+}$ codoped nano- $\mathrm{TiO}_{2}$ photocatalyst was stronger. This is because the absorption band edge redshifted obviously, and the spectral response range was extended into the visible light region, increasing the utilization of visible light. $\mathrm{Fe}^{3+} / \mathrm{La}^{3+}$ codoped nano- $-\mathrm{TiO}_{2}$ photocatalyst showed superior photocatalytic performance compared to the single-doped samples. Because nano- $\mathrm{TiO}_{2}$ codoped with two elements can achieve higher catalytic activity under visible light, this approach increases the potential utility of nano- $\mathrm{TiO}_{2}$ photocatalyst materials in important environmental purification processes. 
TABLE 2: Results of first-order kinetic fitting of the data for methyl orange degradation under visible light irradiation with the different doped nano- $\mathrm{TiO}_{2}$ catalysts.

\begin{tabular}{|c|c|c|c|c|c|}
\hline Photocatalyst & $\mathrm{Kr}$ & $R$ & SD & $N$ & $P$ \\
\hline $0.6 \% \mathrm{La}-\mathrm{TiO}_{2}$ & 0.1336 & 0.9977 & 0.0189 & 6 & $<0.0001$ \\
\hline $0.01 \% \mathrm{Fe}-\mathrm{TiO}_{2}$ & 0.0671 & 0.9961 & 0.0125 & 6 & $<0.0001$ \\
\hline $0.6 \% \mathrm{La} 0.01 \% \mathrm{Fe}-\mathrm{TiO}_{2}$ & 0.1041 & 0.9967 & 0.0177 & 6 & $<0.0001$ \\
\hline
\end{tabular}

\section{Conflict of Interests}

The authors declare no conflict of interests.

\section{Acknowledgments}

This research is financially supported by the Scientific Research Foundation of Chongqing University of Arts and Sciences (R2014CH08), the Science and Technology Project from Chongqing (cstc2014jcyjA20023), the National Training Programs of Innovation and Entrepreneurship for Undergraduates (201410642003), and the Chongqing Training Programs of Innovation and Entrepreneurship for Undergraduates (201410642008).

\section{References}

[1] A. L. Giraldo, G. A. Peñuela, R. A. Torres-Palma, N. J. Pino, R. A. Palominos, and H. D. Mansilla, "Degradation of the antibiotic oxolinic acid by photocatalysis with $\mathrm{TiO}_{2}$ in suspension," Water Research, vol. 44, no. 18, pp. 5158-5167, 2010.

[2] L. Rizzo, A. D. Sala, A. Fiorentino, and G. Li Puma, "Disinfection of urban wastewater by solar driven and UV lamp- $\mathrm{TiO}_{2}$ photocatalysis: effect on a multi drug resistant Escherichia coli strain," Water Research, vol. 53, pp. 145-152, 2014.

[3] H. Tong, S. Ouyang, Y. P. Bi, N. Umezawa, M. Oshikiri, and J. H. Ye, "Nano-photocatalytic materials: possibilities and challenges," Advanced Materials, vol. 24, no. 2, pp. 229-251, 2012.

[4] C. E. Barrera-Díaz, V. Lugo-Lugo, and B. Bilyeu, "A review of chemical, electrochemical and biological methods for aqueous Cr(VI) reduction," Journal of Hazardous Materials, vol. 223-224, pp. 1-12, 2012.

[5] V. K. Gupta, "Application of low-cost adsorbents for dye removal-a review," Journal of Environmental Management, vol. 90, no. 8, pp. 2313-2342, 2009.

[6] I. Nandi, P. Mitra, P. Banerjee, A. Chakrabarti, M. Ghosh, and S. Chakrabarti, "Ecotoxicological impact of sunlight assisted photoreduction of hexavalent chromium present in wastewater with zinc oxide nanoparticles on common Anabaena flosaquae," Ecotoxicology and Environmental Safety, vol. 86, pp. 7$12,2012$.

[7] Y. M. Tzou, S. L. Wang, and M. K. Wang, "Fluorescent light induced $\mathrm{Cr}(\mathrm{VI})$ reduction by citrate in the presence of $\mathrm{TiO}_{2}$ and ferric ions," Colloids and Surfaces A: Physicochemical and Engineering Aspects, vol. 253, no. 1-3, pp. 15-22, 2005.

[8] L. Liu, Z. Ji, W. Zou et al., "In situ loading transition metal oxide clusters on $\mathrm{TiO}_{2}$ nanosheets as co-catalysts for exceptional high photoactivity," ACS Catalysis, vol. 3, no. 9, pp. 2052-2061, 2013.

[9] M. A. Barakat, "New trends in removing heavy metals from industrial wastewater," Arabian Journal of Chemistry, vol. 4, no. 4, pp. 361-377, 2011.
[10] P. S. Suchithra, C. P. Shadiya, A. P. Mohamed, P. Velusamy, and S. Ananthakumar, "One-pot microwave mediated growth of heterostructured ZnO@AlSi as a potential dual-function ecocatalyst for treating hazardous pollutants in water resources," Applied Catalysis B: Environmental, vol. 130-131, pp. 44-53, 2013.

[11] V. V. Guliants, M. A. Carreon, and Y. S. Lin, "Ordered mesoporous and macroporous inorganic films and membranes," Journal of Membrane Science, vol. 235, no. 1-2, pp. 53-72, 2004.

[12] A. Idris, E. Misran, and N. Mohd Yusof, "Photocatalytic reduction of $\mathrm{Cr}(\mathrm{VI})$ by PVA-alginate encapsulated $\gamma \mathrm{Fe}_{2} \mathrm{O}_{3}$ magnetic beads using different types of illumination lamp and light," Journal of Industrial and Engineering Chemistry, vol. 18, no. 6, pp. 2151-2156, 2012.

[13] R. Gherbi, N. Nasrallah, A. Amrane, R. Maachi, and M. Trari, "Photocatalytic reduction of $\mathrm{Cr}(\mathrm{VI})$ on the new hetero-system $\mathrm{CuAl}_{2} \mathrm{O}_{4} / \mathrm{TiO}_{2}$," Journal of Hazardous Materials, vol. 186, no. 23, pp. 1124-1130, 2011.

[14] D. P. Das, K. Parida, and B. R. De, "Photocatalytic reduction of hexavalent chromium in aqueous solution over titania pillared zirconium phosphate and titanium phosphate under solar radiation," Journal of Molecular Catalysis A: Chemical, vol. 245, no. 1-2, pp. 217-224, 2006.

[15] K. M. Parida, S. S. Dash, and D. P. Das, "Physico-chemical characterization and photocatalytic activity of zinc oxide prepared by various methods," Journal of Colloid and Interface Science, vol. 298, no. 2, pp. 787-793, 2006.

[16] J. Li, T. X. Wang, and X. H. Du, "Preparation of visible lightdriven $\mathrm{SnS}_{2} / \mathrm{TiO}_{2}$ nanocomposite photocatalyst for the reduction of aqueous Cr(VI)," Separation and Purification Technology, vol. 101, pp. 11-17, 2012.

[17] D. W. Chen and K. R. Ajay, "Removal of toxic metal ions from wastewater by semiconductor photocatalysis," Chemical Engineering Science, vol. 56, no. 4, pp. 1561-1570, 2001.

[18] L. Qi, H. Li, and L. Dong, "Simple synthesis of flower-like ZnO by a dextran assisted solution route and their photocatalytic degradation property," Materials Letters, vol. 107, pp. 354-356, 2013.

[19] L. Mohapatra and K. M. Parida, "Zn-Cr layered double hydroxide: visible light responsive photocatalyst for photocatalytic degradation of organic pollutants," Separation and Purification Technology, vol. 91, pp. 73-80, 2012.

[20] J. Hirayama, R. Abe, and Y. Kamiya, "Combinational effect of $\mathrm{Pt} / \mathrm{SrTiO}_{3}: \mathrm{Rh}$ photocatalyst and $\mathrm{SnPd} / \mathrm{Al}_{2} \mathrm{O}_{3}$ nonphotocatalyst for photocatalytic reduction of nitrate to nitrogen in water under visible light irradiation," Applied Catalysis B: Environmental, vol. 144, pp. 721-729, 2014.

[21] D. Dimitrakopoulou, I. Rethemiotaki, Z. Frontistis, N. P. Xekoukoulotakis, D. Venieri, and D. Mantzavinos, "Degradation, mineralization and antibiotic inactivation of amoxicillin by UV$\mathrm{A} / \mathrm{TiO}_{2}$ photocatalysis," Journal of Environmental Management, vol. 98, no. 1, pp. 168-174, 2012. 
[22] M. Chen and W. Chu, "Degradation of antibiotic norfloxacin in aqueous solution by visible-light-mediated $\mathrm{C}-\mathrm{TiO}_{2}$ photocatalysis," Journal of Hazardous Materials, vol. 219-220, pp. 183-189, 2012.

[23] S. Yahiat, F. Fourcade, S. Brosillon, and A. Amrane, "Removal of antibiotics by an integrated process coupling photocatalysis and biological treatment-case of tetracycline and tylosin," International Biodeterioration \& Biodegradation, vol. 65, no. 7, pp. 997-1003, 2011.

[24] D. Nasuhoglu, A. Rodayan, D. Berk, and V. Yargeau, "Removal of the antibiotic levofloxacin (LEVO) in water by ozonation and $\mathrm{TiO}_{2}$ photocatalysis," Chemical Engineering Journal, vol. 189190, pp. 41-48, 2012.

[25] N. A. Ramos-Delgado, M. A. Gracia-Pinilla, L. Maya-Treviño, L. Hinojosa-Reyes, J. L. Guzman-Mar, and A. HernándezRamírez, "Solar photocatalytic activity of $\mathrm{TiO}_{2}$ modified with $\mathrm{WO}_{3}$ on the degradation of an organophosphorus pesticide," Journal of Hazardous Materials, vol. 263, pp. 36-44, 2013.

[26] J. Wang, W. Sun, Z. Zhang et al., "Preparation of Fe-doped mixed crystal $\mathrm{TiO}_{2}$ catalyst and investigation of its sonocatalytic activity during degradation of azo fuchsine under ultrasonic irradiation," Journal of Colloid and Interface Science, vol. 320, no. 1, pp. 202-209, 2008.

[27] C.-H. Chiou and R.-S. Juang, "Photocatalytic degradation of phenol in aqueous solutions by $\mathrm{Pr}$-doped $\mathrm{TiO}_{2}$ nanoparticles," Journal of Hazardous Materials, vol. 149, no. 1, pp. 1-7, 2007.

[28] M. Stylidi, D. I. Kondarides, and X. E. Verykios, "Visible light-induced photocatalytic degradation of Acid Orange 7 in aqueous $\mathrm{TiO}_{2}$ suspensions," Applied Catalysis B: Environmental, vol. 47, no. 3, pp. 189-201, 2004. 

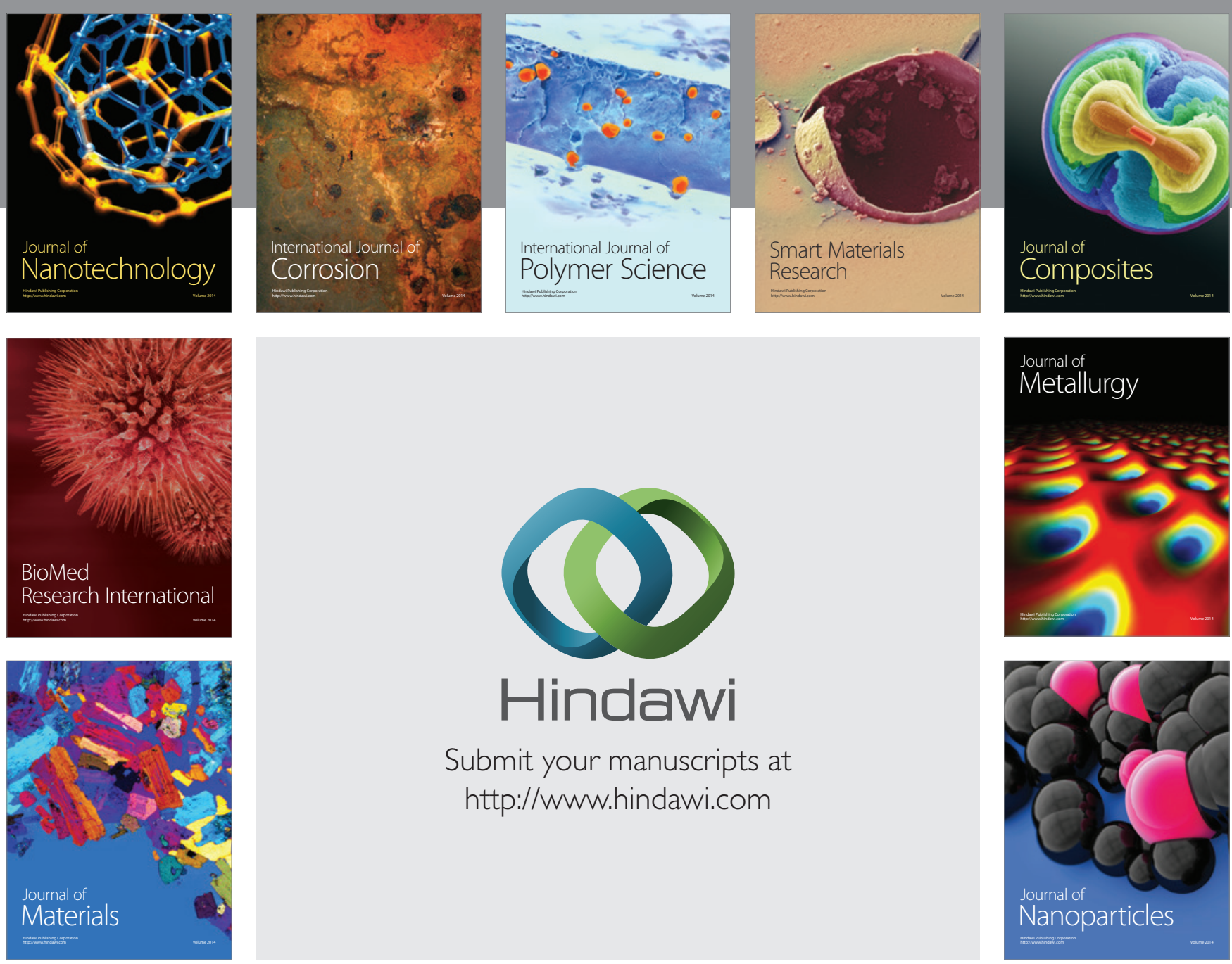

Submit your manuscripts at http://www.hindawi.com
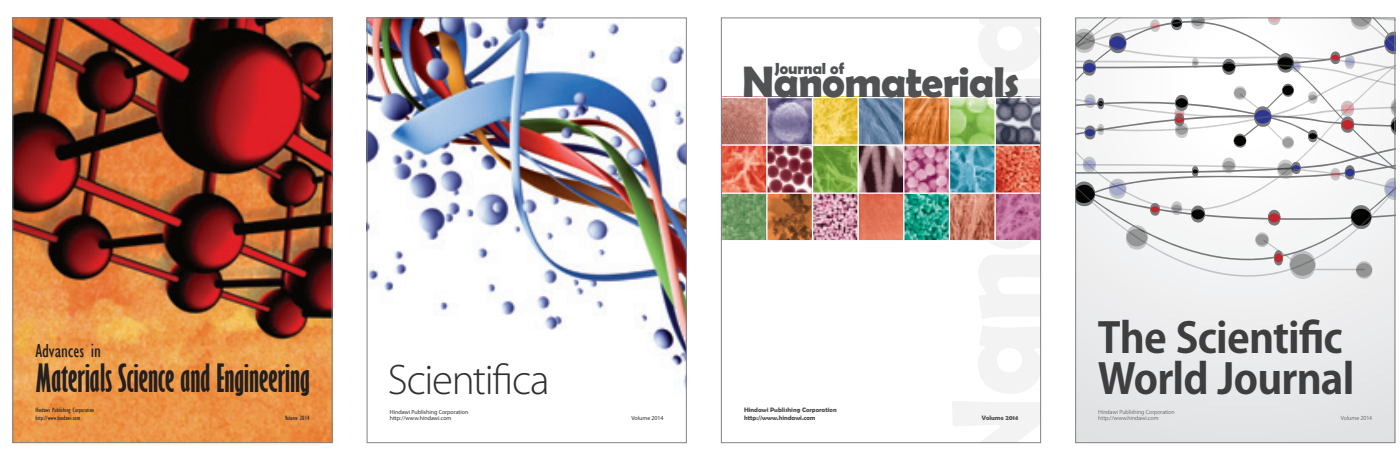

\section{The Scientific World Journal}
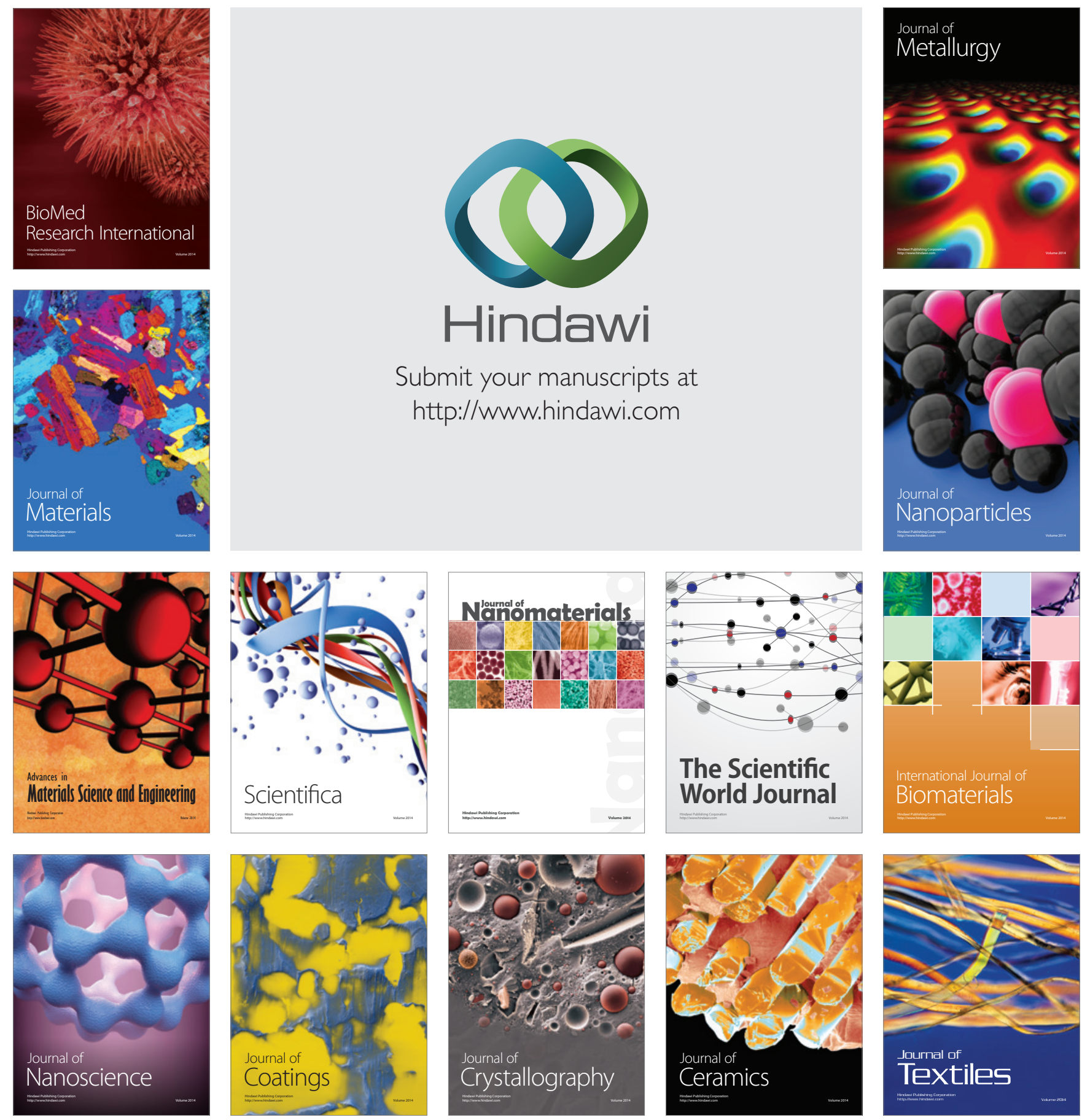